\title{
Phasic Dopamine Release in Appetitive Behaviors and Drug Addiction
}

\author{
Matthew J. Wanat*, Ingo Willuhn, Jeremy J. Clark and Paul E.M. Phillips
}

Department of Psychiatry and Behavioral Sciences and Department of Pharmacology, University of Washington, Seattle, WA 98195, USA

\begin{abstract}
Although dopamine is implicated in the development of addiction, it is unclear how specific dopamine release patterns are involved with drug seeking. Addictive drugs increase tonic dopamine levels on the order of minutes, as well as phasic dopamine release events that occur on a subsecond time scale. Phasic dopamine release is associated with the initiation of goal-directed behaviors, and has been shown to promote drug seeking. Prior experience with addictive drugs modulates the synaptic and intrinsic properties of dopamine neurons, affects the pattern of dopamine neuron firing and release, and alters dopamine-dependent behaviors related to drug addiction. In this review, we synthesize the known drugdependent changes to the dopamine system along with the established functions of phasic dopamine release in order to provide a framework for conceptualizing the role of phasic dopamine release in drug addiction. Because drug addiction is commonly thought to involve changes in brain circuits important for natural reinforcement, we first present the role of phasic dopamine release in appetitive and goal-directed behaviors in the context of contemporary theories regarding the function of dopamine. Next, we discuss the known drug-induced changes to dopamine neurons and phasic release in both in vitro and in vivo preparations. Finally, we offer a simple model that chronic drug experience increases the contrast, or 'signal to noise', of phasic dopamine release to basal dopamine levels in response to drug-related stimuli, which could result in aberrant associations between cues and reinforcers that contribute to the development of addiction.
\end{abstract}

Keywords: Dopamine, drug abuse, addiction, voltammetry.

Numerous theories have been developed to model aspects of drug addiction, both from a psychological [1-4] and a neurochemical perspective [2, 5-10]. In particular, the dopamine system is thought to play an important role in addiction [2, 5-10]. With the development of techniques that can analyze subsecond neurotransmitter release events in behaving rodents, it has become evident that phasic, subsecond dopamine release is involved with promoting drug seeking [11], as well as other appetitive [12,13] and goal-directed behaviors that do not involve abused substances [14-18]. While others have established theories regarding the role of dopamine in the development of addiction [2, 5-10], there has been far less theoretical discussion on the specific function of phasic dopamine release in regards to drug abuse. In this review, we provide background on the dopamine system, describe methods used to detect dopamine release, and discuss current theories about dopamine's role in behavior. Because addiction is commonly thought to usurp the neural circuitry involved with natural reinforcement [2] and learning and memory [5, 6], we will first discuss the role of phasic dopamine release in appetitive and learned goal-directed behaviors that do not involve abused substances. Finally, we will summarize the changes to the dopamine system after drug exposure in rodents and humans, review studies that explicitly examined drug-dependent effects on phasic dopamine release, and suggest how drug-dependent alterations in the dopamine system could affect phasic dopamine signaling. The goal of this review is to extend upon existing theories of dopamine function in addiction and provide a conceptual framework

*Address correspondence to this author at the Department of Psychiatry and Behavioral Sciences, Health Sciences Building, Box 356560, 1959 NE Pacific St., Seattle, WA 98195, USA; Tel: 206.265.0827;

Fax: 206.543.9520; E-mail: wanat@u.washington.edu for the role of phasic dopamine release in drug-related behaviors.

\section{THE DOPAMINE SYSTEM: ANATOMY, RECORDINGS, AND DETECTION}

\section{Anatomy}

The ventral tegmental area (VTA) and the neighboring substantia nigra pars compacta $(\mathrm{SN})$ contain the primary dopamine-producing neurons in the brain [19]. The VTA is thought to play a particularly important role in drug abuse [7]. The SN has been examined far less in the context of addiction, with many studies focusing on its role of in motor control [20]. A large proportion of the neurons whose cell bodies are in the VTA contain dopamine. For example, in the rat, $2 / 3$ of the approximately 40,000 VTA neurons contain tyrosine hydroxylase, the rate-limiting enzyme in dopamine synthesis, and as such are presumably dopaminergic [19, 21]. The non-dopamine producing cells in the VTA are likely $\gamma$-aminotbutyric acid (GABA)- and glutamateproducing; however, there is some debate whether glutamate and dopamine are co-released from the same neurons [22, 23 ] or if glutamate and dopamine neurons exist in distinct populations [24]. A typical VTA neuron will project to only a single nucleus, though there is considerable variability between VTA-projection targets in the percentage of VTA neurons that are dopamine-producing [19]. Specifically, of the VTA neurons projecting to the nucleus accumbens (NAcc), $\sim 85 \%$ are dopamine-producing, while $\sim 50 \%$ of the neurons projecting to the amygdala are dopamine-producing, and $\sim 30 \%$ of the neurons projecting to the prefrontal cortex (PFC) are dopamine-producing [19]. As with its projections, the VTA receives input from a diverse array of brain regions including the PFC, NAcc, bed nucleus of the stria terminalis, lateral dorsal tegmentum (LDT), pedunculopontine 
tegmental nucleus (PPT), amygdala and areas of the hypothalamus [25-28]. Thus, the VTA is a heterogeneous brain region with extensive afferent input and efferent projections.

\section{Dopamine Neuron Recordings}

In extracellular electrophysiological studies, dopamine neurons are identified in vivo primarily based on the presence of a triphasic and long-duration action potential waveform [29, 30]. These neurons exist in one of three states: (1) hyperpolarized and quiescent, (2) firing singlespike action potentials in regular or irregular patterns at relatively low rates $(2-10 \mathrm{~Hz})$, or (3) firing action potentials in bursts up to $15-30 \mathrm{~Hz}[29,31,32]$. Reports suggest that a large portion of dopamine neurons may be electrically coupled [33, 34], which could aid in the synchronicity of dopamine neuron firing patterns. While dopamine neuron firing patterns are often further categorized for subsequent analysis [31, 32, 35, 36], it is important to note that a given dopamine neuron can both fire in a single-spike pattern, as well as in bursts [37]. Furthermore, the amount of bursting can vary considerably across neurons, and as such, the degree of bursting may be more appropriately viewed as a continuum [37]. The burst firing of dopamine neurons requires glutamatergic input, activation of N-methyl-Daspartate (NMDA) receptors, opening of high-threshold calcium currents, and finally activation of calcium-activated potassium currents to terminate the burst [38]. Furthermore, activation of brainstem nuclei such as the PPT and LDT are involved in dopamine neuron burst generation [38, 39] and increased dopamine levels in the NAcc and striatum [27, 40]. Although robust immunohistochemical methods can identify dopamine, GABA, and glutamate neurons in the VTA [24], electrophysiological identification of neuronal subtypes using only the action potential waveform can be problematic [41]. In vivo juxtacellular labeling of recorded VTA neurons in the rat demonstrate that many neurons with a triphasic and long-duration waveform actually are not dopaminergic [42], although it has been suggested that these findings are difficult to interpret because of methodological considerations [30]. Dopamine neuron firing patterns have been examined in vivo both in anesthetized and awake, behaving preparations. Although the patterns of dopamine neuron firing are similar (e.g. single-spike and burst firing) whether the recordings are performed in awake or anesthetized rodents, it should be noted that anesthesia can affect certain pharmacological responses [43] and reduce the number of spontaneously active and bursting dopamine neurons when compared to recordings in awake preparations [32, 44, 45].

In contrast to in vivo recordings, dopamine neurons in brain slice preparations do not spontaneously fire action potentials in bursts, but rather typically exhibit regular action potential firing [46]. The reported frequency of putative dopamine neuron firing in the slice varies whether one uses extracellular (3-8 Hz) [46], perforated-patch $(2-5 \mathrm{~Hz})$ [47], or whole-cell recordings $(1-3 \mathrm{~Hz})[41,48]$. Regardless of the recording technique, the firing of putative GABA neurons is significantly greater than dopamine neurons and is usually higher than $10 \mathrm{~Hz}$ [46]. Although the firing rate can provide a crude segregation of neuronal subtypes in brain slices, a more reliable electrophysiological marker of dopamine neurons was found to be the presence of the hyperpolarization-activated, cyclic nucleotide-regulated cation current $\left(I_{\mathrm{h}}\right)$ [46]. However, subsequent work determined that not all cells with the $I_{\mathrm{h}}$ produced dopamine [41, 49], which may be explained by differences between species, as TH is present in $98 \%$ of VTA neurons with the $I_{\mathrm{h}}$ in the mouse [48], but only in $\sim 50 \%$ in the rat [41]. Recent studies highlight that the electrophysiological properties and pharmacological manipulations can identify dopamine neuron content in brain slices if the projection target of the neuron is known [50, 51]. Although electrophysiological characteristics may not always be an accurate predictor of dopamine neurons, the $I_{\mathrm{h}}$ is commonly used as a marker of dopamine content in many brain slice electrophysiological studies.

\section{Detecting Dopamine Levels}

Microdialysis and fast-scan cyclic voltammetry (FSCV) are the two primary analytical techniques commonly used to detect dopamine levels in vivo. Microdialysis involves the perfusion of fluid through an implanted probe with an inlet port, outlet port, and a dialysis membrane [52]. Small molecules in close proximity to the outside of the probe can diffuse through the dialysis membrane to be collected in the dialysate fluid on the inside of the probe for subsequent analysis. A more accurate estimate of the concentration of a specific analyte around the probe can be determined by using no net flux microdialysis. This variation of conventional microdialysis involves perfusing known concentrations of the analyte of interest through the probe. If the input analyte concentration is higher relative to the extracellular space, the analyte will diffuse out of the probe leading to a lower output analyte concentration in the dialysate. Conversely, if the input analyte concentration that flows into the probe is lower relative to the extracellular space, the analyte will diffuse into the probe leading to a higher output analyte concentration in the dialysate. The estimated analyte concentration in the brain is found at the point where there is no net flux, or rather diffusion, of the analyte across the microdialysis probe. While microdialysis provides excellent analyte selectivity and sensitivity, there are a few drawbacks associated with this technique. For example, microdialysis probes are relatively large in diameter $(200-300 \mu \mathrm{M})$, which can disrupt tissue for up to $1.4 \mathrm{~mm}$ from the probe location [53]. While it was originally thought that an accurate measurement of absolute analyte levels could be achieved using either no net flux or low perfusion rate microdialysis preparations [52], the damage due to the probe size can lead to lower estimates of the analyte concentration [54]. Another issue with microdialysis is its temporal resolution, which typically is on the order of minutes, though recent attempts have improved the resolution for some analytes to as low as $14 \mathrm{~s}[52,55]$. Therefore, microdialysis is not well suited to examine analyte changes to behaviorally relevant discrete stimuli, but rather is adept at identifying basal or slow/tonic changes in analyte levels, often on a minute time scale. For the purpose of this article, we will use the expression 'basal dopamine levels' to refer to dopamine that is detected primarily with microdialysis in the absence of any overt behaviorally relevant stimuli or acute experimenter-induced treatment (pharmacological or electrical), and is thought to be around 5-20 $\mathrm{nM}$ in the NAcc [56]. Importantly, basal 
dopamine levels are related to the number of spontaneously active dopamine neurons, as well as to the firing pattern and firing rate of dopamine neurons under these conditions [57].

In contrast to microdialysis, electrochemical techniques offer excellent temporal resolution to isolate phasic neurotransmitter release events but are less selective at differentiating between certain analytes of interest. When used to detect dopamine, electrochemical techniques take advantage of the fact that application of a modest potential $(\sim 200 \mathrm{mV} v s \mathrm{Ag} / \mathrm{AgCl})$ to a suitable electrode is sufficient to drive electrolysis of dopamine to dopamine-o-quinone [58]. The current produced by the electrolysis can be measured at the electrode and is proportional to the number of molecules undergoing oxidation (i.e. dopamine to dopamine-oquinone), and therefore the concentration at the electrode surface. Different command waveforms can be used for the application of the potential to the electrode, the simplest being a continuous, constant potential in (constant-potential) amperometry. This variant has microsecond temporal resolution and is often used to study the kinetics of dopamine release and reuptake; however, it offers little chemical selectivity since any oxidized compound will be detected with constant-potential amperometry recordings, which has deterred researchers from using this technique in behaving animals. A more selective electrochemical method is fastscan cyclic voltammetry (FSCV), which utilizes a triangle input waveform to separate the electrolysis from different analytes into temporally-resolved peaks in the output current. Since the voltage is swept to an oxidizing potential and back, current is generated (in opposite directions) during the oxidation and reduction processes, whereby producing two electrochemical peaks for a given compound making chemical resolution more robust. FSCV can be employed to record dopamine release in awake, behaving rodents [59-61], and is capable of detecting changes in dopamine levels that occur in the range of 0.1 to $100 \mathrm{~s}$ [62]. Using FSCV recordings in the NAcc, it was found that brief electrical activation $(<1 \mathrm{~s})$ of the dopamine system transiently elicited a phasic increase in dopamine levels up to $1 \mu \mathrm{M}$ in awake, behaving rodents, although the increase is smaller in anesthetized preparations [63, 64]. For the purpose of this article, we will use the expression 'phasic' to refer to dopamine that is detected on the order of seconds with electrochemical techniques and 'tonic' to refer to dopamine that is detected on the order of minutes with microdialysis. While electrical stimulations of the midbrain that mimic the burst firing frequency of dopamine neurons elicits a greater summation of dopamine release relative to regularly-spaced lower-frequency stimulations [64], it is important to note that the specific firing pattern responsible for phasic dopamine release is currently unknown. For example, phasic dopamine release could potentially arise from dopamine neurons burst firing, or firing single-spikes in a coordinated fashion, or some combination of both. Regardless, many studies have been able to examine the function of the dopamine system using microdialysis to assess basal or slow/tonic changes in dopamine levels, and electrochemistry to identify phasic dopamine release events.

\section{THE ROLE OF DOPAMINE IN APPETITIVE AND GOAL-DIRECTED BEHAVIORS: PHARMACOLOGY, ELECTROPHYSIOLOGY, AND GENETIC APPROACHES}

Since the identification of dopamine over 50 years ago [65], a number of theories have been developed to explain the role of dopamine in appetitive and goal-directed behaviors. We will briefly discuss some of the prominent theories and the supporting evidence to provide a framework for understanding the current views of dopamine function. We would like to preface that these theories are not necessarily mutually exclusive, but rather they provide different perspectives on the role of dopamine in behavior. More in depth discussion on theories of dopamine function can be found elsewhere [66-71].

The most well-established and uncontroversial theory of dopamine function is that dopamine release is involved with sensorimotor behaviors $[66,68]$. Dopamine plays a key role in motor tasks, as this is the primary deficit observed with those suffering from Parkinson's Disease (PD), a disease that leads to the selective degeneration of dopamine neurons [72]. However, it should be noted that symptoms of PD do not typically appear until a majority of SN dopamine neurons and terminals have degenerated [20, 73]. Furthermore, mice that are deficient in dopamine production are catatonic and require supplements for survival and normal motor behaviors [74].

In addition to enabling normal motor activity, many lines of evidence support a critical role of dopamine in motivation $[66,68]$. For example, manipulations that mildly impair dopamine signaling in the NAcc without altering motor behavior have been found to shift food consumption from a preferred food option that required lever pressing for receipt toward a less palatable food option that was freely available [75-78]. In another behavioral assay that examined effort and motivation, rats were given an option in a T-maze to obtain a lower food reward with no obstacle or a higher food reward that required climbing over a barrier. Systemic dopamine receptor antagonism $[79,80]$ or local dopamine depletions in the NAcc [81] shifted the response from the high reward side to the low reward side. Importantly, rats still preferred the high reward side when the barrier was removed under conditions when dopamine signaling was impaired, which suggests that these manipulations were not a result of a learning deficit [79-81]. Motivation is also assessed in operant tasks under progressive ratio (PR) reinforcement schedules. Under PR reinforcement paradigms, the operant requirement (often lever pressing) increases on subsequent trials until the 'break-point', which is the number of lever presses for reinforcer delivery on the last completed trial and is a measure motivation [82]. Inhibiting dopamine signaling in the NAcc reduces the break-point for natural reinforcers [82-84]. Conversely, enhancing dopamine signaling in the NAcc by local amphetamine injections [85] or in mice with impaired dopamine transporter function [86] increases the break-point for natural reinforcers. Together, these studies highlight that dopamine, especially within the NAcc, may 
function to overcome the motivational costs required for completing tasks requiring a high level of effort $[68,87]$.

The 'incentive-salience' hypothesis of dopamine builds upon the general motivational hypothesis discussed above [66]. In short, incentive-salience is the neural representation of motivational value generated in response to a rewardrelated stimulus. This motivational representation is dynamic and can be applied to internally generated or externally experienced reward-related stimuli to give the stimulus incentive value, which can take control of behavior. In this hypothesis, it is thought that dopamine modulates the incentive value of reward-related stimuli [66]. This hypothesis separates 'liking' of rewards, as measured by hedonic responses, from 'wanting' of the reward, as measured by motivational metrics [66]. Specifically, a variety of insults to the function of the dopamine system do not affect taste-reactivity or 'liking' [88-90]. Conversely, enhancing dopamine levels in dopamine transporter knockdown mice increases the 'wanting' for natural reinforcers as evidenced by increased break-points under PR reinforcement schedules [86] and shorter latencies to obtain a reinforcer [91]. These general findings have been mirrored in human studies where dopamine levels correspond to self-reports of 'wanting' and not to 'liking' $[92,93]$.

Studies employing electrophysiological recordings of dopamine neurons in awake, behaving animals provide evidence that dopamine can encode a 'prediction-error' signal in the brain [70]. In both primates and rats, it was found that dopamine neurons increase firing to the receipt of a reward, but after training dopamine neurons instead fire to cues that predict the availability of the reward [94, 95]. Interestingly, when a predicted reward is omitted, the firing of dopamine neurons is depressed [95]. Together, this evidence suggests that dopamine neuron firing signals the scalar discrepancy between the actual reward obtained and that predicted [95]. In support, dopamine neuron firing correlates with the probability of reward availability [96], the uncertainty of reward delivery [97], as well as the magnitude of the reward [98]. Some argue that the increase in dopamine neuron firing in these reward-related paradigms occurs too fast for any cortical-mediated computation to occur [67, 99], which suggests that dopamine may be important for performing low computational, sub-cortical-dependent decisions [100]. Alternatively, it has been suggested that dopamine release may function as a novelty signal that reinforces efferent copies of recently completed behaviors [67]. Regardless, dopamine neuron activation in these tasks maps extraordinarily well onto a teaching signal proposed in the theoretical learning models in the field of reinforcement learning $[71,95,101,102]$.

In summarizing the experimental support for the sensorimotor, motivational, incentive-salience, and prediction-error theories of dopamine function, it becomes evident that the dopamine system is associated with a diverse array of natural and appetitive behaviors. Furthermore, dopamine likely subserves various functions depending upon the anatomical location, context, and duration of its release [70]. With this theoretical foundation of dopamine's role in behavior, we will now explore the work that has specifically examined phasic dopamine release in the NAcc during appetitive and goal-directed behaviors.

\section{THE ROLE OF PHASIC DOPAMINE RELEASE IN APPETITIVE AND GOAL-DIRECTED BEHAVIORS: ELECTROCHEMICAL APPROACH}

The prominent theories of dopamine function developed primarily from the findings of pharmacological, genetic, and electrophysiological experimental techniques. However, these techniques do not provide direct information on dopamine release in forebrain terminal regions during discrete behavioral events on a physiological time scale. Pharmacological and genetic manipulations can produce long-lasting or permanent changes, which prevent using these techniques for isolating behavioral effects related to dopamine changes on a subsecond level. While electrophysiological recordings have excellent temporal resolution, it is not a perfect proxy of dopamine concentration since models of release processes incorporate several non-linear functions [103]. There are currently no reliable electrophysiological criteria for determining the projection target of a given VTA neuron based solely on the action potential waveform, which prevents inferring how dopamine neuron firing is associated with release in a specific brain structure. Therefore, voltammetric approaches, such as FSCV, offer an unparalleled capacity to quantitate phasic changes in dopamine concentration in specific target regions occurring on a physiological time scale. These techniques have provided further insights into dopamine's role in the brain during behavior that are complementary to pharmacological, genetic, and electrophysiological methods. Below we will discuss the findings regarding phasic dopamine release in the NAcc using FSCV in drug-free appetitive and goal-directed behaviors.

Presentation of novel sensory stimuli activates the mesocorticolimbic system. Specifically, electrophysiological recordings in both rats and primates indicate that putative dopamine neurons increase their firing rate in response to tactile stimulation [33], presentation of an auditory stimulus [33], or an unexpected delivery of sucrose [95]. In studies utilizing microdialysis, increases in dopamine overflow are observed after handling [104], and during sexual behaviors [105]. Using FSCV recordings in the NAcc, it was demonstrated that the number of spontaneous transient dopamine release events are enhanced six-fold in response to the presentation of another rat $[12,13]$. However, the effect on transient dopamine release events was significantly attenuated with repeated rat presentations, presumably correlating with the reduced novelty and habituation to the other rat [12].

Although the frequency of dopamine transients increased during the presentation of another rat, it is difficult to associate dopamine release to any one specific behavior [12]. Subsequent studies examined phasic dopamine release in response to more easily controlled experimental conditions. Using FSCV, unpredictable intra-oral administration of sucrose was found to increase phasic dopamine release, while administration of an aversive compound, quinine, decreased dopamine release [106]. Interestingly, when rodents self-administered sucrose, dopamine levels increased in response to the presentation of a cue predicting sucrose availability, and the climax of phasically emancipated dopamine in the NAcc coincided with the lever press for sucrose [16]. Control experiments found that unreinforced 
cue presentations did not affect dopamine levels in naïve rats, suggesting that the phasic NAcc dopamine release observed in this task was dependent upon a learned association [16]. Further highlighting a role of phasic dopamine release in learned behaviors, FSCV recordings in the NAcc were made from rats undergoing Pavlovian conditioning where a conditioned stimulus (CS+) reliably predicts reinforcer delivery (unconditioned stimulus, US) $[14,17,18]$. Early in training, phasic dopamine responses are observed primarily to the reward delivery (US). After rats learn the CS-US association, dopamine is released to the presentation of the CS, while the response to the US is attenuated. However, a stimulus that did not predict reward availability (CS-) also increased dopamine release to some degree to the onset and offset of the CS-, suggesting some generalization between the conditioned stimuli [14]. Together, these studies using a between-animal design suggest that there is a transfer of the phasic dopamine response from the US to the CS $[14,18]$ that reflects the electrophysiological recordings in similar paradigms [69, 94]. An important future FSCV experiment would be to utilize a within-animal design so that the time-course of the transfer from the US to the CS could be accurately determined. It should be noted that phasic dopamine release is observed to both the US and CS in rats [14], but dopamine neurons tend to fire only to either the US or the CS in primates [69]. This discrepancy could reflect differences in the species studied, the training paradigm utilized, or functional differences between dopamine neuron firing and release. It should be noted that despite the caveats raised above in relating in vivo electrophysiological data to dopamine release, many of these results in rats obtained using FSCV are consistent with the electrophysiological studies performed in behaving monkeys and rats.

Some studies have examined the role of phasic dopamine release during intra-cranial self-stimulation (ICSS) procedures, where learning to lever press for a highly reinforcing electrical stimulation can be assessed within an animal in a single session $[15,71]$. A recent report found that the magnitude of dopamine released in the NAcc to cues predicting ICSS availability was correlated with the learning to lever press for electrical stimulation [15]. Specifically, cue-evoked dopamine responses increased in magnitude during acquisition, disappeared during extinction, and reappeared upon reinstatement [15]. These results are exciting since they correlate dopamine responses with learning an operant task and also reflect changes in the contigency of the reinforcement. Somewhat analogous to natural rewards, ICSS is dopamine-dependent [107], although sustained phasic dopamine release to the selfstimulation is not required for operant responding in ICSS paradigms [108]. However, caution should be exercised when extending these results to all aspects of natural reinforcers because ICSS removes the sensory component of reward processing.

To summarize, phasic dopamine release using FSCV has been assessed in many appetitive and goal-directed behaviors, and it is apparent that an increase in the number of phasic dopamine events in the NAcc is associated with novelty and unexpected rewards [12-14]. Experiments employing operant tasks also highlight that cues predicting reinforcer availability elevate dopamine release in the NAcc
$[15,16]$, where the increase in dopamine precedes the operant action [16, 109]. Studies involving Pavlovian conditioning also suggest that phasic dopamine is released primarily to the US early in training and to the CS after extensive training [14, 18]. Therefore, phasic dopamine release is associated with motor output, motivation, the value of reward-related stimuli, and learning. Further experiments with multiple reward magnitudes will be required to determine if phasic dopamine release can also function as a prediction-error signal [69]. In addition to its role in appetitive and goal-directed behaviors, many lines of evidence support a critical role of the dopamine system in addiction-related behaviors [7]. Furthermore, a prevalent theory posits that addiction results in part from pathological changes in brain systems important for reinforcement [2]. Below, we will discuss the effect of addictive drugs on the dopamine system, highlight how drugs alter dopamine neurotransmission, and suggest how these changes, especially to phasic dopamine release, could modulate behavior in regards to drug abuse.

\section{THE EFFECT OF ABUSED SUBSTANCES ON DOPAMINE NEURONS: ELECTROPHYSIOLOGY AND MICRODIALYSIS STUDIES}

\section{Acute Effects of Abused Drugs on Midbrain Dopamine Neurons in Drug-Naïve Rodents}

In order to understand the role of dopamine in drug abuse, it is important to first discuss how drugs affect the dopamine system acutely, after multiple drug exposures, and after withdrawal from multiple drug exposures. Studies employing microdialysis techniques demonstrate that noncontingent administration of abused drugs such as alcohol, nicotine, opiates, psychostimulants, and cannabinoids increase dopamine levels in the NAcc [110, 111], while drugs with low potential for abuse do not affect dopamine overflow [110]. The cellular mechanism by which addictive drugs increase dopamine levels depends upon the drug studied. Psychostimulants such as amphetamine and cocaine enhance dopamine overflow by affecting dopamine clearance from the extracellular space [112, 113]. Opiates and cannibinoids activate dopamine neurons through inhibition of local GABA input [114-117]. Similar to opiates, ethanol reduces the firing of VTA GABA neurons [118], but also directly modulates the excitability of dopamine neurons [119-121]. Additionally, ethanol affects the excitatory and inhibitory synaptic inputs onto VTA dopamine neurons [122, 123]. Nicotine activates and desensitizes dopamine neurons and inhibitory inputs to dopamine neurons in the VTA [124, 125], but prolonged nicotinic receptor activation is thought to cause a net excitatory effect on the dopamine system that may involve changes in presynaptic glutamate release $[124,126]$. Regardless of the cellular mechanism, in vivo and in vitro recordings of dopamine neurons demonstrate that noncontingent peripheral administration of alcohol [119], nicotine [35, 125], opiates [114, 115], and cannabinoids $[127,128]$ increase dopamine neuron firing. Furthermore, nicotine [35], opiates [114], and cannabinoids [127] all increase the burst firing of dopamine neurons. Conversely, dopamine neuron firing is attenuated after administration of cocaine [129, 130] and amphetamine [131] in anesthetized animals and brain slices, due to the autoinhibitory effects of 
dopamine at high concentrations after psychostimulant exposure [129].

Before summarizing the changes to the dopamine system brought about by multiple drug exposures, we would like to highlight that a majority of the studies examined the effect of psychostimulants. Furthermore, it is difficult to parsimoniously reconcile all of the findings in the literature. While an acute exposure to abused drugs elicits clearly identified effects on dopamine neuron firing and dopamine levels, the effect of multiple drug exposures on the dopamine system is far more complicated in part because of differences arising from the drug studied, how the drug is administered (dose, frequency, and route), and the duration after drug experience. Few consistent trends are found in the literature regarding the effect of multiple drug exposures on the dopamine system, but as we will discuss, there are often difficulties with the interpretation of the data due to methodological limitations.

\section{Acute Effects of Abused Drugs on the Dopamine System in Drug-Experienced Rodents}

To our knowledge, only a couple of studies have examined dopamine neuron firing patterns during drug selfadministration. In rats that self-administered heroin, dopamine neurons increased their firing only after the first heroin infusion in a session [132, 133]. All subsequent heroin infusions were characterized by an increase in dopamine neuron firing before the infusion, which was immediately followed by a decrease in dopamine neuron firing rate after the infusion [132, 133]. While the electrophysiological data is lacking, more is known regarding how dopamine levels are affected by a drug treatment in drug-experienced rodents. Cocaine administered chronically via the experimenter [134-136] or through rodent self-administration [135, 137, 138] augments dopamine levels in response to a subsequent cocaine administration. Furthermore, microdialysis studies demonstrate that rodents titrate their drug intake to maintain a stable elevation of dopamine levels whether the drug administered is cocaine [137, 139], amphetamine [140], or heroin [141].

\section{The Effect of Withdrawal After Chronic Drug Treatment on Dopamine Neuron Firing}

The effect of withdrawal after chronic drug treatment has been extensively studied in addiction research, though unfortunately a number of administration paradigms have been used so that it is often difficult to compare the findings between studies. For the simplicity and clarity of this discussion, 'chronic' drug treatment refers to any treatment that involved more than one prior drug exposure and 'withdrawal' refers to the period of time after the drug treatment, which does not necessarily signify the presence of overt aversive symptoms or a physiological syndrome. Dopamine neuron firing rate is reduced by chronic treatment of nicotine after 1-day withdrawal [142], ethanol after acute (up to 24 hrs) withdrawal [143, 144], and morphine up to a week of withdrawal [145, 146], but see [147]. Additionally, acute withdrawal from chronic ethanol treatment reduces the number of spontaneously active dopamine neurons [148], as well as the burst firing of dopamine neurons [144], while chronic morphine treatment reduces dopamine burst firing for up a week of withdrawal treatment [145, 146], but see
[147]. Interestingly, a 1-day withdrawal after chronic cannabinoid treatment reduced burst firing in SN dopamine neurons, but was without effect on dopamine burst firing in the VTA, or on basal dopamine neuron firing rate in either the SN or VTA [149]. It should be noted that some of the changes in dopamine neuron firing patterns discussed above return to baseline levels within two weeks after cessation of the drug treatment $[142,145]$.

In contrast to the effects with ethanol, nicotine, morphine, and cannabinoids, chronic treatment with psychostimulants can increase the activity of dopamine neurons during early withdrawal. Specifically, withdrawal (1 - 3 days) after multiple injections of amphetamine reduced the autoinhibitory effects of dopamine receptor activation (subsensitivity) [150-153], which can even lead to an increase in dopamine neuron firing rate with a subsequent amphetamine challenge [151], even though amphetamine acutely reduces dopamine neuron firing in naïve subjects [131]. However, the effects on the dopamine system depend upon the dose of amphetamine administered [150]. Similar to amphetamine, 1-day withdrawal after chronic noncontingent cocaine administration reduced the autoinhibitory effects of dopamine receptor activation, and increased the number of spontaneously active dopamine neurons, as well as the firing rate and burst firing of dopamine neurons [154]. These changes in dopamine neuron properties were found to last for up to 3 days of withdrawal in rats that had selfadministered cocaine [155]. Interestingly, the number of spontaneously active dopamine neurons in the VTA was reduced compared to control-treated rats following 2 weeks of withdrawal after chronic non-contingent cocaine treatment [156]. Another study found that 1-week withdrawal from chronic non-contingent intraperitoneal cocaine injections did not affect SN dopamine neurons, but increased the number of spontaneously active dopamine neurons in the VTA [157]. However, 1-week withdrawal after continuous cocaine infusions reduced the number of active $\mathrm{SN}$ dopamine neurons and reduced the bursting of VTA dopamine neurons [157]. Therefore, the changes on the dopamine system elicited by drugs are highly dependent upon the route of administration [157].

To summarize, relatively short withdrawal periods (less than 2 weeks) after chronic drug treatment can elicit a variety of effects on dopamine neuron activity that depends upon the drug studied, the dose administered, the route of administration, and the location of the recorded dopamine neurons. However, a few trends have emerged from these studies. First, a transient decrease in dopamine neuron activity is observed within 1 week of withdrawal after chronic treatment of ethanol, nicotine, opiates, and cannabinoids. Second, chronic psychostimulant treatment increases dopamine neuron activity for at least up to 3 days of withdrawal, which may involve subsensitivity of dopamine autoreceptor function. Third, chronic psychostimulant treatment can decrease dopamine neuron activity after longer periods of withdrawal.

A critical aspect of drug addiction is the high prevalence of relapse and the difficulty of abstaining from drug use over extended periods of time $[158,159]$. It has been suggested that the intense craving for drugs contributes to relapse [160]. Interestingly, drug-craving is progressively enhanced 
after longer periods of withdrawal in rodent models of addiction [161]. A recent report found that longer periods of withdrawal $(3-6$ weeks) after chronic non-contingent treatment of nicotine, amphetamine, cocaine or ethanol all reduced the number of spontaneously active dopamine neurons, which perhaps is important in the development of drug craving [162]. Regardless, more studies are needed in order to adequately examine this hypothesis.

\section{The Effect of Withdrawal After Chronic Drug Treatment on Tonic Dopamine Levels}

A large number of studies have examined how withdrawal after drug treatment affects the mesocorticolimbic system. As discussed in the previous section, some trends are evident in the effect of withdrawal on dopamine neuron activity; however, few trends are apparent when examining the literature that has studied the effect of withdrawal on dopamine overflow. Using conventional microdialysis, no net flux microdialysis, or examining tritiated dopamine levels, many have reported that withdrawal from chronic drug treatment decreases basal concentration of dopamine [144, 163-169], while others report no change in basal dopamine levels [134, 135, 143, $163,170-176]$, and yet others found an increase in basal dopamine levels [164, 173, 177, 178]. While some studies reported that basal dopamine levels changed depending upon the duration of withdrawal [164, 173], these observed changes were not consistent across studies. For example, some report that withdrawal after chronic cocaine exposure decreases basal dopamine levels in as early as a few hours [169] to as long as 10 days [165], while others found increases in basal dopamine levels during $1-4$ days of withdrawal [164, 173, 178], and it was reported to have no effect on basal dopamine levels between 24 hours and 2 weeks of withdrawal [134, 135]. Thus, at least for cocaine, no clear temporal effect of withdrawal on basal dopamine levels can be inferred from these studies.

While basal dopamine levels after withdrawal from chronic drug treatment have been assessed with both conventional and no net flux microdialysis, the no net flux method can be more accurate at determining exact dopamine levels immediately surrounding the microdialysis probe [56]; however, it often is not used in behaving rodents because the temporal resolution is relatively poor compared to conventional microdialysis strategies. Some studies employing no net flux microdialysis did not observe any changes in dopamine levels after withdrawal from drug treatment $[134,170,172,173]$, while another found an increase [165], though it was suggested that differences in the buffer composition and flow rate could account for this discrepancy [134]. Interestingly, in a study using no net flux microdialysis, the lack of an effect of withdrawal from cocaine treatment on dopamine levels was accompanied by lower dopamine uptake, which was hypothesized to denote a reduction in basal dopamine levels [170]. Furthermore, some studies have utilized both conventional and no net flux microdialysis and came to different conclusions depending upon the technique used. Withdrawal from drug treatment increased basal dopamine levels when studied with conventional microdialysis, but was without effect when using no net flux microdialysis [134, 173]. Because of the divergent results between conventional and no net flux microdialysis techniques, it is difficult to state with resolve whether withdrawal from chronic drug exposure has a conclusive effect on basal dopamine levels.

In addition to basal dopamine levels, many studies have examined how withdrawal after chronic drug treatment affects drug-stimulated dopamine overflow. Some reported a decrease in drug-stimulated dopamine levels that was evident between 1 - 9 days of withdrawal [134, 135, 168, $173,176,179-181]$, although these changes may be transient $[173,179]$. Others have found that early withdrawal (3 - 7 days) after amphetamine treatment does not affect drugstimulated dopamine overflow $[153,182,183]$. While many report increases in drug-induced dopamine levels after withdrawal $[134,153,163,173,174,177-179$, 182-184], though the timing of these effects varies considerably. One consistent trend is that chronic amphetamine treatment does not affect drug-stimulated dopamine levels early in withdrawal ( 1 - 4 days), but augments amphetaminestimulated dopamine levels reliably after $2-4$ weeks of withdrawal [153, 182-184]. However, there is less agreement between studies in regards to chronic cocaine treatment. Specifically, some reports suggest that chronic cocaine treatment has little effect on drug-induced dopamine levels after 1 day of withdrawal, but robustly increases drugstimulated dopamine overflow after 3 weeks of withdrawal [174, 185], while others report the opposite [178]. Additionally, some have found that chronic cocaine treatment augments drug-stimulated dopamine levels immediately and for up to 3 weeks $[134,179]$.

While we have discussed the effects of withdrawal on basal and drug-stimulated dopamine levels separately, it is important to note that these two measures are intertwined. Chronic cocaine treatment was found to increase both basal and cocaine-stimulated dopamine levels after 1-day withdrawal compared to saline-injected controls, but the percentage increase in dopamine levels was significantly less in the cocaine-treated rats [178]. Conversely, a study using a binge cocaine administration protocol reported a decrease in basal dopamine levels, and a lower concentration of dopamine in response to an acute cocaine injection [169]. However, when the effect of a challenge cocaine exposure was presented as a percentage of basal dopamine levels, the cocaine-stimulated dopamine levels were significantly enhanced [169]. Although these two studies found different effects of previous cocaine exposure on basal and drugstimulated dopamine levels presumably due to variations in drug administration protocols [169, 178], they both highlight that it is exceedingly difficult to interpret the findings from many microdialysis studies that present findings only as percent changes because it is unknown how the respective drug treatments may affect basal dopamine levels.

While some of the discrepancies between studies could be explained by the method of presenting the data, it is important to note that the effects on dopamine levels after withdrawal from chronic drug treatment depends upon the drug studied, as clear differences exist even between psychostimulants [134, 153, 173, 174, 178, 179, 182-184]. Additionally, the dose of the drug administered during the chronic treatment can differentially alter dopamine neuron firing [150] and levels [134]. Another potential source of variability in the reported findings could arise from different 
drug-dependent effects in distinct striatal subregions [163, $169,171,177,179]$, which was not explicitly examined in many studies.

Yet another explanation for the lack of cohesion amongst many of these studies can be due to the fact that detecting dopamine levels depends upon three major components: (i) the basal level of dopamine, which was discussed above, (ii) the quantity of dopamine released, and (iii) the uptake of dopamine. Although this section has focused on changes in dopamine levels determined by microdialysis, this technique is not capable of examining changes in the quantal size of dopamine levels. Therefore, we will briefly mention that in a study using FSCV, it was inferred that prior cocaine experience and 2 weeks of withdrawal led to an increased size of the releasable pool of dopamine [186]. A number of studies have observed changes in dopamine transporter number and function in the NAcc during withdrawal after chronic drug treatment. Specifically, the number of dopamine transporters increase while cocaine is present [187] and return to baseline levels for up to a week of withdrawal [163, 188]. However, dopamine transporter numbers are lower after $10-21$ days of withdrawal [187, 189-191]. Some studies suggest that there is a functional impairment in dopamine uptake during 1- 7 days of withdrawal [163, 192, 193], although the time course of this effect does not match with the fluctuations in dopamine transporter numbers.

To summarize, many studies have examined the effect of withdrawal after chronic drug treatment on dopamine levels; however, few clear trends are evident. Many of the differences between seemingly similar studies may result from different treatment schedules, locations of the microdialysis probe, as well as the specific microdialysis technique employed. Additionally, caution must be exercised when comparing between treatment groups when microdialysis data is presented only as a percentage change from baseline dopamine levels, as the percentage change in dopamine overflow is directly related to basal dopamine levels [169, 178]. Furthermore, dopamine release is also regulated by quantal size and the function and number of dopamine transporters. Therefore, many of the discrepancies between the studies discussed above may reflect complex interactions between the specific drug-treatment, where dopamine is released, and the dynamics of dopamine clearance.

\section{THE EFFECT OF ABUSED SUBSTANCES ON THE SYNAPTIC INPUTS TO DOPAMINE NEURONS}

As discussed above, dopamine burst firing requires glutamatergic input, NMDA receptor activation, opening of high-threshold calcium currents, and finally activation of calcium-activated potassium currents to terminate the burst [38]. Thus, it follows that changes in synaptic inputs, calcium currents, or calcium-activated potassium currents could alter burst patterns of firing in dopamine neurons. Although incomplete, a growing body of evidence suggests that abused drugs can modify synaptic inputs onto dopamine neurons, as well as the currents found in dopamine neurons important for burst generation. For example, many studies have now shown that a single non-contingent injection of cocaine increases the ratio of $\alpha$-amino-3-hydroxy-5- methylisoxazole-4-propionic acid (AMPA) receptor currents to NMDA receptor currents (AMPA/NMDA) on VTA dopamine neurons [8, 194-199]. This effect is observed 24 hours after the cocaine injection, persists for up to 5 days, and is observed in rodents that received a single [198] or chronic non-contingent cocaine treatment [195]. Furthermore, The AMPA/NMDA ratio is thought to be a reliable measure of excitatory synaptic strength, where increases have been associated with enhanced AMPA receptor function [194, 198, 200]. In agreement with enhanced excitatory synaptic function on dopamine neurons, a single cocaine injection also increased the frequency and amplitude of miniature excitatory post-synaptic currents [198]. Furthermore, increases in the AMPA/NMDA ratio are associated with an impaired ability to generate long-term potentiation (LTP), a cellular mechanism that strengthens excitatory synapses and is thought to be important in learning and memory [6, 198]. Thus, an enhanced AMPA/NMDA ratio is likely occluding the ability to elicit LTP because the excitatory synapse cannot be further strengthened [6, 198]. However, for the purpose of this discussion, we highlight that such augmentations in the AMPA/NMDA ratio will promote the efficacy of excitatory inputs to dopamine neurons.

While much of the work examining synaptic alterations on dopamine neurons has focused on the effects of cocaine, similar increases in the AMPA/NMDA ratio on VTA dopamine neurons have been observed $24 \mathrm{hrs}$ after a single injection of amphetamine, nicotine, or morphine [197]. Subsequent work demonstrated that these synaptic changes are rapid, as an enhanced AMPA/NMDA ratio is observed 2$3 \mathrm{hrs}$ after injection of cocaine and amphetamine [201, 202]. Interestingly, in vitro exposure to cocaine transiently increases NMDA receptor currents [203] and increases the AMPA/NMDA ratio after 3-5 hrs [201], although this may not extend to all psychostimulants [202].

Many studies examining drug-mediated changes on VTA dopamine neuron synaptic plasticity utilized non-contingent drug-administration, though recent studies have now examined these synaptic changes under conditions where rodents self-administer the drug. For example, an increase in VTA AMPA receptor levels is observed in rats that have self-administered nicotine [204]. Interestingly, food, sucrose, and cocaine self-administration increase the AMPA/NMDA ratio immediately after training, but rats that selfadministered cocaine (and not yoked controls) exhibited a persistent increase in the AMPA/NMDA ratio [205]. This study highlights how the changes on VTA dopamine neurons will depend upon the method of drug administration, as chronic peripheral injection of cocaine transiently $(<10$ days) affects the AMPA/NMDA ratio [195], though these changes are longer lasting (> 21 days) in self-administering rodents [205]. Originally, it was hypothesized that these changes in glutamate receptor function are responsible for behavioral sensitization, which is an enhanced motor response to a subsequent drug exposure [198]. Instead, further studies found that the AMPA/NMDA ratio is not associated with the development of behavioral sensitization [195, 199], but rather may be important for initiating longlasting changes, which promote addiction-like behaviors [205, 206]. 
Recently, addictive drugs have been shown to affect inhibitory synaptic inputs on VTA dopamine neurons. Multiple injections of cocaine [196] and a single injection of morphine [207] reduce the inhibitory input on VTA dopamine neurons. These effects are not unitary across drugs, as a single injection of ethanol was found to increase inhibitory input on VTA dopamine neurons [208, 209]. However, withdrawal after chronic ethanol exposure promotes burst firing of dopamine neurons by inhibiting the function of calcium-activated potassium currents [210]. These studies suggest that exposure to addictive substances can strengthen excitatory synaptic input, reduce inhibitory synaptic input, and alter the function of ion currents in VTA dopamine neurons. While these drug-induced adaptations have not been characterized or identified for all addictive substances, we suggest that these changes will increase efficacy of excitatory inputs on VTA dopamine neurons, which could increase the coordinated activity of VTA dopamine neurons and/or the burst firing of VTA dopamine neurons [211], since this firing pattern is dependent upon glutamatergic input, NMDA receptor activation, and calcium-activated potassium currents [38]. We therefore would expect that behaviorally relevant and drug-associated stimuli would enhance phasic dopamine release to a greater level after experience with drugs. Empirical data of dopamine neuron firing patterns in awake, behaving rodents after drug exposure is lacking, though recent studies have begun to examine these questions by examining phasic dopamine release with FSCV in rodents during drug-related behaviors.

\section{THE EFFECT OF ABUSED SUBSTANCES ON PHASIC DOPAMINE RELEASE}

FSCV has been utilized to examine phasic dopamine release in a variety of model systems, though it is important to note that drug-mediated alterations in dopamine release can result from direct effects on dopamine neuron excitability or from changes in dopamine uptake. Numerous studies have examined the effect of ethanol on dopamine release in striatal brain slices from drug-naïve rats. Specifically, moderate doses of ethanol are without effect on dopamine uptake [212-214]. In contrast, chronic ethanol vapor exposed rats exhibited enhanced dopamine uptake in vitro, which was thought to be a compensatory mechanism resulting from the elevated dopamine levels due to the prolonged ethanol treatment [215]. In awake and behaving rodents, acute peripheral injections of ethanol at doses that increase tonic dopamine neuron firing were found to attenuate electrically stimulated dopamine release [216]. This ethanol-mediated reduction of phasic dopamine release was thought to result from enhanced tonic dopamine levels that impaired phasic dopamine release due to the depletion of releasable dopamine and activation of release-regulating autoreceptors [216]. However, intravenous ethanol infusions sometimes increased the frequency of spontaneous phasic dopamine transients in awake, behaving rats [217]. Similar effects have also been observed with cannabinoid receptor activation, where intravenous infusions of cannabinoids reduced electrically stimulated dopamine release, but increased the frequency and amplitude of spontaneous phasic dopamine release events [218]. These findings with ethanol and cannabinoid administration highlight that it can be difficult to parsimoniously use the findings from in vitro preparations and artificial electrical stimulations to predict the net effect in awake, behaving rodents. Reduced preparations and electrical stimulations are better suited to examine specific aspects of dopamine transmission, such as the involvement of specific ion channels, changes in release kinetics and the quantity of dopamine release, which are more difficult to accurately ascertain using in vivo preparations. Regardless, these findings highlight that ethanol and cannabinoids produce changes in phasic dopamine release.

A number of studies have examined the effect of nicotine on phasic dopamine release in both in vitro and in vivo preparations. In contrast to ethanol, acute in vivo nicotine exposure enhances dopamine uptake in the striatum [219]. Nicotine exerts frequency-dependent effects on phasically stimulated dopamine release in vitro, where at low firing rates dopamine release is attenuated, but at high firing bursts nicotine enhances dopamine release [220, 221]. Intravenous infusions of nicotine were also found to increase the frequency and amplitude of spontaneous phasic dopamine release events [217]. In agreement with the findings from other abused substances, intravenous infusions of cocaine also increase spontaneous phasic dopamine release events in the NAcc [62, 217, 222-224]. Interestingly, endogenous cannabinoids modulate the cocaine-, nicotine-, and ethanolmediated increases in phasic dopamine release, as the effects of drugs on phasic dopamine release are attenuated by systemic cannabinoid receptor antagonism [217]. While the locus of this effect is yet to be determined, it is speculated that it lies within the VTA, where cannabinoid receptor activation reduces GABA release onto VTA dopamine neurons [225]. Together, these findings suggest that abused drugs may exert similar effects on phasic dopamine release even though their respective cellular targets are quite distinct. Future studies are required to systematically examine drug-specific effects on phasic dopamine release. Below we discuss the effects of cocaine on phasic dopamine release, as this has been the most thoroughly studied addictive substance.

Using microdialysis, it was found that an acute administration of abused drugs increase dopamine levels to a greater extent in a limbic structure, such as the NAcc, relative to a motor brain structure, such as the dorsal caudate nucleus [110], although this may not be valid for amphetamine [226]. Furthermore, a meta-analysis of microdialysis studies indicate that cocaine augments dopamine overflow preferentially within the NAcc shell relative to the NAcc core [227]. Consistent with microdialysis findings, a recent report using FSCV identified larger cocaine-mediated effects on phasic dopamine release in the NAcc shell compared to the NAcc core [222]. It was suggested that the preferential effect on dopamine release in the NAcc shell by cocaine could be critically important for the primary reinforcing effects of drug [222]. Similar to differential effects of contingent and non-contingent drug administration on synaptic plasticity on VTA dopamine neurons [205], the effect of cocaine infusions on phasic dopamine release can depend upon the contingency of the administration [223]. No changes in dopamine levels are observed within $10 \mathrm{~s}$ of a non-contingent cocaine administration to awake, drug-naïve rats. However, phasic 
dopamine events are increased during this time frame with contingent cocaine administration, highlighting that these early dopamine release events ( $<10 \mathrm{~s}$ after drug delivery) may be important for learned associations, and are not a result of the pharmacological actions of cocaine [223]. Identical to natural reinforcers $[15,16]$, cues that predict cocaine availability are able to elicit phasic dopamine release that persist even when the drug is not administered [11, 224]. Interestingly, the rise in dopamine levels is associated with the initiation of approach to lever press for cocaine $[11,223$, 224], which is thought to be causal since stimulation of dopamine neurons was found to promote this behavior [11]. To summarize, cues associated with drug reinforcers elicits phasic dopamine release $[11,223,224]$, similar to what was observed with natural reinforcers [14, 16-18]. In contrast to natural reinforcers, acute administration of addictive substances promotes spontaneous phasic dopamine release events [217], which could be involved with establishing and strengthening associations between environmental cues and the drug.

The field of FSCV recordings in behaving rodents during drug-related behaviors is nascent, and many questions regarding the prolonged effects of drugs on phasic dopamine release remain unanswered. One limitation present in many behavioral studies using FSCV arises from the usage of acute glass-insulated microelectrodes, which need to be physically inserted on each recording day. Due to this approach with acute recordings, FSCV recordings are likely in different locations across days, and successfully inserting electrodes becomes more difficult after multiple recording sessions [61]. We have developed chronically implanted microelectrodes that permit stable FSCV recordings over multiple days and are well suited to address changes in phasic dopamine release over long-lasting behavioral paradigms [228]. Future studies employing chronically implanted FSCV electrodes will be able to test for changes in the pattern of phasic dopamine release during the transition to compulsive drug taking in rodent models of addiction.

\section{CHANGES IN DOPAMINE NEUROTRANSMISSION IN HUMAN ADDICTS}

The development of human imaging techniques, such as functional magnetic resonance imaging (fMRI) and positron emission tomography (PET), have provided many insights into functional changes within the brain that occur in human addicts [229]. Specifically, fMRI identifies changes in blood oxygen levels, thought to represent changes in neural activity, with a time resolution of a few seconds. In contrast, PET can be used to make specific measurements of neurotransmission by monitoring radiotracers that selectively bind to proteins. For example, radiolabeled dopaminereceptor ligands can be monitored in the brain, and their concentration decreases as they are displaced from receptors following release of endogenous dopamine. Alterations in radioligand binding is often indicative of changes in receptor levels, though it should be noted that changes in the receptor affinity for a radioligand could confound these results. The temporal resolution for PET is in minutes and only increases, not decreases, in dopamine concentration can be detected [10]. As we will describe below, human addicts and rodents exhibit similar alterations in dopamine neurotransmission, though it is important to remember that the temporal resolution of the identified changes are much lower in human studies (seconds to minutes) compared to those using FSCV in rodent models of addiction (subsecond).

While it is well established that the delivery of natural positive reinforcers increases dopamine neuron firing [94, 95] and subsequent release in the striatum [14, 16-18, 106], this was only recently demonstrated in humans using fMRI and PET [230, 231]. Furthermore, exposure to psychostimulants increased dopamine levels in the human striatum that was associated with the reinforcing effects of the drug [232-234], which mirrors the findings from microdialysis and FSCV studies performed in rodents [110, 217].

In addition, the changes to the dopamine system after withdrawal from chronic drug experience are quite similar between rodents and humans. Specifically, stimulated dopamine release was reduced in detoxified cocaine abusers [235], consistent with the attenuated drug-stimulated dopamine overflow in rodents after chronic cocaine exposure found in some studies [135, 178, 180]; however, as discussed above, there is little consensus between many of the studies in the rodent literature. The level of radiolabeled dopaminereceptor ligands under basal conditions has also proved useful in assessing difference in neural function between individuals. Human abusers of alcohol [236], cocaine [237], heroin [238], and methamphetamine [239] have lower levels of dopamine receptor binding compared to non-abusers. In contrast, individuals that are resistant to drug use (close relatives of addicts that do not abuse drugs) exhibit increased dopamine receptor binding, suggesting that higher levels of dopamine receptors in the striatum could protect against the development of addiction [240]. In agreement with human studies, the amount of drug consumed is inversely related to the amount of dopamine receptor binding in the striatum in both rodent [241] and non-human primate addiction studies [242]. These findings have led to the hypothesis that low numbers of dopamine receptors, especially within the striatum, whether due to genetics or previous drug exposure, can make an individual more susceptible to drug abuse [9, $10,229,242,243]$. Furthermore, the attenuated activity of dopamine neurons [156,162] and reduced basal dopamine levels [164-167] found in rodents in withdrawal from chronic drug treatment is consistent with the hypofunctional dopamine system that is observed in human addicts [10].

Recent human imaging studies have provided insights into the neurochemical events responsible for drug craving, which is thought to be a key contributor to relapse. Specifically, exposure to drug-related cues is thought to promote drug craving in human addicts [244-247], as well as in rodents [7, 161]. Presentation of conditioned cues associated with alcohol [245, 246], nicotine [248], amphetamine [249], and cocaine [247] were all found to increase dopamine transmission in the striatum of humans, consistent with rodent studies using FSCV [11, 223, 224]. In summary, human imaging studies have provided evidence that drugs and drug-associated cues increase dopamine levels and that chronic drug exposure is associated with an impaired function of the dopamine system, which together recapitulates many of the conclusions from the rodent addiction studies discussed above. 


\section{THE 'SIGNAL TO NOISE' MODEL OF PHASIC DOPAMINE SIGNALING IN DRUG ADDICTION}

Briefly, we will summarize what we have discussed in this review and offer our model regarding the role of phasic dopamine release in the development of drug abuse, which we have also schematically presented in Fig. (1). In the absence of behaviorally relevant stimuli in a drug-naïve condition, dopamine neurons will fire action potentials in either single-spike or burst patterns [29, 31, 32], which will contribute to the basal dopamine levels in brain regions receiving dense dopamine input, such as the NAcc. Many lines of evidence suggest that behaviorally relevant and salient stimuli can increase the firing rate of dopamine neurons [31, 33, 94, 95], which may or may not include an increase in burst firing. For clarity, we do not discriminate between transient increases in single-spike firing rate and burst firing, and represent both as a cluster of action potentials in Fig. (1). Furthermore, exposure to salient stimuli also enhances phasic dopamine release $[12,14,17$, 18 ], which is likely due to synchronous firing of dopamine neurons $[33,34]$ in single-spikes, bursts, or a combination of both (Fig. 1). However, in a drug-naïve state, the presentation of stimuli associated with drug intake, such as drug paraphernalia or cues predicting drug availability, will not affect dopamine neuron firing or release [11].

In contrast to the drug-naïve state, a number of changes occur within the dopamine system whereby an arbitrary stimulus (drug paraphernalia or cues predicting drug availability) becomes behaviorally-relevant and elicits phasic dopamine release after the association is learned between a cue predicting drug availability and the drug itself [11]. It is important to note that this phenomenon is also observed with learned cue-reinforcer associations with natural and nondrug reinforcers [14-16]; however, cues predicting drug availability appear to be more resistant to extinction than cues predicting non-drug reinforcer availability [15, 224], which suggests that additional changes occur in the dopamine system due to the drug experience. In support, learning an association between cues and natural reinforcers transiently affects the synaptic properties of dopamine neurons $[17,205]$, while drug experience promotes longlasting changes (days to weeks) to the intrinsic and synaptic properties of dopamine neurons [198, 205, 210]. Furthermore, dopamine release is thought to modulate synaptic inputs to striatal neurons by inhibiting weak glutamatergic signals and strengthening strong glutamatergic inputs $[250,251]$. Therefore, we posit that these prolonged cellular adaptations in dopamine neurons after withdrawal from chronic drug experience will function to (i) increase the efficacy of excitatory glutamatergic inputs onto dopamine neurons that can increase dopamine neuron firing and subsequent release in response to previously weak or neutral stimuli, which will (ii) strengthen previously learned associations, and (iii) develop and strengthen new associations between environmental cues and drugs. Together, these neural changes will enhance the phasic dopamine 'signal' elicited by drug-related cues after withdrawal from chronic drug experience (Fig. 1).

Furthermore, changes to the 'noise', or rather basal dopamine levels, may in turn amplify the effect of withdrawal on the enhanced dopamine 'signals', leading to a greater 'signal to noise' of phasic dopamine release. Before discussing the experimental support for this analogy, we want to clarify that references to dopamine 'noise' are not meant to imply that basal dopamine levels are without behavioral importance, but rather are only used to conceptualize the contrast of phasic dopamine release events to background dopamine levels. Recently, it was reported that dopamine neuron population activity is attenuated $3-6$ weeks after the cessation of chronic drug treatment in rodents (represented by Neuron 3 in Fig. 1), which may suggest a reduction in the dopamine system 'noise' [162]. Although there is debate regarding the role of chronic drug treatment on dopamine levels throughout the striatum in many rodent studies (see above, and dashed lines in Fig. 1), both human and rodent studies have observed a reduction in stimulated dopamine release $[135,178,180,235]$ and dopamine receptor levels [236-239, 241] after withdrawal from chronic drug treatment, which is consistent with an attenuation of dopamine 'noise'. Together, these findings provide evidence that withdrawal from drugs enhances the contrast, or 'signal to noise' of phasic dopamine release to basal dopamine levels.

We predict that this augmented 'signal to noise' of phasic dopamine release will have important behavioral consequences, especially in regards to drug abuse. Because phasic dopamine release is associated with initiating goaldirected behaviors [11, 16, 223], it follows that the enhanced 'signal to noise' of phasic dopamine signaling will promote drug seeking in response to drug-related stimuli, which is important in the development of addiction. In agreement, human imaging studies find that the presentation of drugrelated cues promotes drug craving [244-247] and increases dopamine transmission [245-249].

A corollary of our hypothesis is that chronic drug exposure will also affect the processing of cue-related associations that do not involve drugs. As discussed above, drug experience promotes long-lasting synaptic changes on dopamine neurons, which we have posited will increase the efficacy of excitatory glutamatergic inputs that can increase dopamine neuron firing and subsequent release to previously weak stimuli. However, the studies that determined the presence of drug-dependent synaptic changes on dopamine neurons were performed in brain slices [198, 205]; therefore, it is difficult to ascertain whether the synaptic changes are global (as schematically presented in Fig. 1), or if the alterations occur on just a subset of dopamine neurons that are preferentially activated by drug-related stimuli. In support of global changes in cue-related associations after drug exposure, amphetamine pre-treatment promotes habit formation after reinforcer devaluation [252], and enhances both inhibitory and excitatory Pavlovian associations [185, 253]. Furthermore, human addicts and healthy subjects with reduced dopaminergic function exhibit impaired decisionmaking abilities [254-256], highlighting that dysregulation of the dopamine system can alter cognition and behavior. Therefore, addiction can be debilitating for individuals because chronic drug experience not only promotes drug seeking, but also affects proper decision-making.

Because drug exposure produces gross synaptic changes on dopamine neurons [198, 205], we suggest that this would elicit a global enhancement in establishing cue-reinforcer 


\section{Drug-naïve}
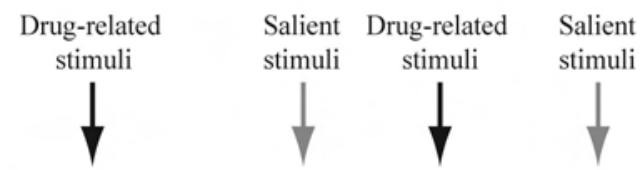

Dopamine neuron firing

Neuron 1

Neuron 2

Neuron 3

Phasic ('signal')

Dopamine released
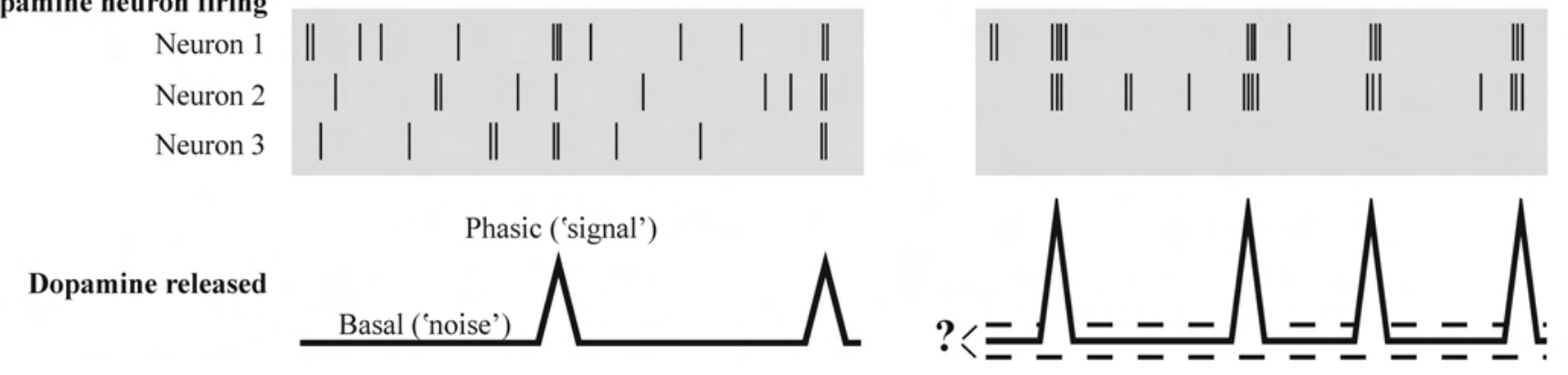

\section{Drug-free after chronic drug experience}
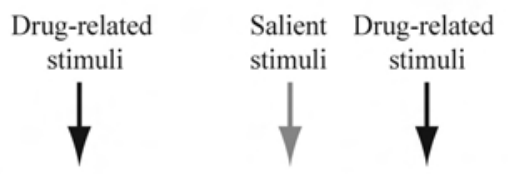

Salient stimuli

Fig. (1). Schematic representation of changes to the dopamine system after chronic drug experience. (Left) Illustration of the firing patterns of three hypothetical dopamine neurons from a drug-naïve individual where each vertical line represents an action potential. For clarity, there is no distinction between transient increases in firing rate and burst firing, as both are represented by a cluster of action potentials. The specific firing patterns responsible for phasic dopamine release are unknown, but phasic release likely results from coordinated activity of dopamine neurons firing in single-spikes and/or bursts. Notice that behaviorally relevant salient stimuli elicits coordinated activity of dopamine neurons that translates into a phasic increase in dopamine release that could occur in brain regions receiving VTA input, such as the NAcc. However, presentation of drug-related stimuli are without effect on dopamine neuron firing and release in the drug-naïve condition. (Right) After withdrawal from chronic drug treatment, dopamine neuron firing rate and population activity can be reduced, which is represented by fewer spontaneous action potentials and the lack of activity in Neuron 3. While the effect on basal dopamine levels remains controversial, many studies demonstrate instrinsic and synaptic changes on dopamine neurons that could promote the efficacy of glutamatergic inputs on to dopamine neurons. We hypothesize that these intrinsic and synaptic changes will increase dopamine neuron firing and phasic release in response to drug-related stimuli. We propose that this increased 'signal to noise' of phasic dopamine release to basal dopamine levels contributes to the aberrent processing of drug-related stimuli, which in turn can promote drug seeking.

associations (Fig. 1). It could be argued that a nondiscriminate enhancement of cue-reinforcer associations would increase the magnitude of all cue-elicited behaviors to similar levels, independent of whether the cue was drugrelated [161] or not [185, 252, 253]. Although it is plausible, there is no evidence to our knowledge of drugs altering the synaptic inputs of dopamine neurons that are preferentially activated by drug-related cues. A global increase in the magnitude of all cue-elicted behaviors initially seems to conflict with the theory that drug-related cues gain increased salience over non-drug cues [66]. However, addictive substances elicit spontaneous phasic dopamine release events [217], which we suggest could promote the quantity of associations between environmental cues and the drug. While the magnitude of all cue-reinforcer associations would be elevated during withdrawal from chronic drug treatment, there would be a greater quantity of associations between drug-related cues and drugs compared to non-drug-related cue-reinforcer associations, which is consistent with an increased salience of drug-related over non-drug-related cues [66]. Furthermore, if phasic dopamine release acts as a teaching signal, the sustained pharmacological response to abused drugs should continue to update the weight of drugrelated cues, whereas phasic dopamine released under normal circumstances will attenuate naturally and does not promote sustained learning [257].
We have sought to propose a model that provides evidence at the cellular and system's levels to explain how drug-related cues promote drug seeking through an increase in the 'signal to noise' of phasic dopamine release after withdrawal. Breaking the link between drug-related cues and drug seeking is an attractive target for therapeutic interventions to reduce the incidence of relapse in human addicts. However, there is also considerable interest in determining the neurochemical changes associated with the development or initiation of addiction-related behaviors. Acute drug administration increases both basal dopamine levels and phasic dopamine release [11, 110, 217, 222-224], which at first pass seems incompatible with our 'signal to noise' model since both the 'signal' and the 'noise' are elevated. However, voltammetric studies measure phasic changes in analyte levels relative to basal levels; hence, voltammetry techniques specifically measure an enhancement of a phasic 'signal' relative to basal 'noise'. Dopamine is phasically released to cues predicting reinforcer availability in a number of reinforcement learning paradigms $[14,15,17,223]$; therefore, it is possible that the drugdependent elevations of phasic dopamine release events could promote the association of cues and drug reinforcement [257]. However, a critical future experimental question will be to determine if phasic dopamine release is indeed necessary and sufficient for reinforcement learning. 
Throughout this review, we have focused primarily on the effects of abused drugs on dopamine neuron firing, as well as dopamine levels and release. However, it is important to note that dopamine exerts a number of postsynaptic effects throughout the mesocorticolimbic system, which been described in detail elsewhere [23, 250, 251]. Furthermore, the time course of dopamine's effects can range from milliseconds to minutes [23, 70]. Dopamine release in the striatum is suggested to strengthen strong glutamatergic inputs and inhibit weak inputs [250, 251], which provides a plausible general postsynaptic effect of dopamine that is complementary to our 'signal to noise' model of phasic dopamine release after chronic drug treatment. While we have discussed basal dopamine levels and phasic dopamine release separately, it is important to note that basal levels and phasic release are intertwined. Increasing basal dopamine levels activates dopamine autoreceptors, which will open potassium channels that will hyperpolarize dopamine neurons [258], and inhibit phasic dopamine release [259]. Although we have presented a simple model of increased 'signal to noise' of phasic dopamine release, the postsynaptic effects of dopamine are likely complex and will depend upon the amount of dopamine released as well as the region studied.

\section{CONCLUSIONS}

Our model posits that after withdrawal from chronic drug treatment, the 'signal to noise' of phasic dopamine release is enhanced, which promotes aberrant stimulus-reinforcer associations that are important in the development of addiction. Our model fits within the framework of many contemporary theories of dopamine function. Specifically, the increase in the 'signal to noise' of phasic dopamine signaling could be interpreted as an enhanced motivation to pursue drugs [68], or may reflect a potentiation in the incentive-value of drug-related stimuli [66], or could provide a 'prediction-error' teaching signal that reinforces certain behaviors [69]. Our model is also consistent with theories regarding the role of dopamine in learning [67, 71]. Specifically, the increased 'signal to noise' of phasic dopamine release may be important for learning cuereinforcer associations with an acute drug administration, and may also strengthen previously learned cue-reinforcer associations after withdrawal from chronic drug treatment. Regardless, our model proposes that an enhanced 'signal to noise' in phasic dopamine release after chronic drug experience will promote drug seeking and aberrant behaviors related to cue-stimuli associations.

Many theories have been developed to model aspects of drug addiction, both from a psychological and a neurochemical level. Recent psychologically-based reviews suggest that addiction results from changes in the decision making process [3], or that drug craving and substance use are related to an attentional bias toward drug-related cues [1, 4], or involves a decrease in brain reward function with an increase in antireward systems [2]. Neurochemically-based reviews have highlighted important roles of synaptic plasticity [8], learning and memory [6], or changes in neurotransmitter function $[2,9,10]$ in the development of addiction-related behaviors. Furthermore, many have highlighted important roles of the dopamine system in the development of addiction [2,5-10], although it is clear that other neurotransmitter systems and brain regions are involved [7]. Our model complements and extends upon many of established theories regarding the role of dopamine in addiction. Synaptic changes on dopamine neurons and an altered function of the dopamine system have been suggested to be critical in drug addiction [8-10], but we synthesize components of these theories with the extensive literature to make specific hypotheses regarding the function of phasic dopamine release in regards to addiction-related behaviors. Regardless, future studies will be needed to test the predictions in our 'signal to noise' model. The study of phasic dopamine release during behavior is nascent; however, recent improvements in FSCV recording strategies from our lab now permit voltammetric recordings over months [228], which will be an invaluable experimental technique to specifically examine the role of phasic dopamine release in the development of addiction-related behaviors.

\section{Learning Objectives}

- The basic anatomy of the VTA dopamine system and common methods to detect dopamine neurons and dopamine release.

- The evidence supporting contemporary theories of dopamine function.

- The role of phasic dopamine release in appetitive and goal-directed behaviors.

- The acute and prolonged effect of abused drugs on dopamine neuron properties, dopamine neuron firing and dopamine release.

- The effect of abused drugs on phasic dopamine release.

\section{Future Research Questions:}

- Do dopamine neuron firing patterns change in awake, behaving rodents after withdrawal from chronic drug exposure?

- Do the patterns and amplitude of phasic dopamine release change after withdrawal from chronic drug exposure?

- Is learning associations between cues and non-drug reinforcers affected in a phasic dopamine-dependent manner after chronic drug exposure?

- Is the association between phasic dopamine release and reinforcement learning a causal relationship?

\section{ACKNOWLEDGMENTS}

We would like to thank the all of the reviewers of this manuscript, whom provided excellent input on this article. This work was completed while under the support of National Institute of Health funds: T32-AA009455 (MJW), F32-DA024540 (JJC), R21-DA021793 (PEMP), and R01MH079292 (PEMP).

\section{REFERENCES}

[1] Franken IH. Drug craving and addiction: integrating psychological and neuropsychopharmacological approaches. Prog Neuropsychopharmacol Biol Psychiatry 2003; 27(4): 563-79.

[2] Koob GF, Le Moal M. Addiction and the brain antireward system. Annu Rev Psychol 2008; 59: 29-53.

[3] Redish AD, Jensen S, Johnson A. A unified framework for addiction: vulnerabilities in the decision process. Behav Brain Sci 2008; 31(4): 415-37; discussion 37-87.

[4] Weinstein A, Cox WM. Cognitive processing of drug-related stimuli: the role of memory and attention. Journal of psychopharmacology (Oxford, England). 2006 Nov; 20(6): 850-9. 
[5] Hyman SE. Addiction: a disease of learning and memory. Am J Psychiatry 2005; 162(8): 1414-22.

[6] Hyman SE, Malenka RC, Nestler EJ. Neural Mechanisms of Addiction: The Role of Reward-Related Learning and Memory. Annu Rev Neurosci 2006.

[7] Kalivas PW, McFarland K. Brain circuitry and the reinstatement of cocaine-seeking behavior. Psychopharmacology (Berl) 2003; 168(1-2): 44-56.

[8] Kauer JA, Malenka RC. Synaptic plasticity and addiction. Nat Rev Neurosci 2007; (11): 844-58.

[9] Volkow ND, Fowler JS, Wang GJ. The addicted human brain viewed in the light of imaging studies: brain circuits and treatment strategies. Neuropharmacology 2004; 47 Suppl 1: 3-13.

[10] Volkow ND, Fowler JS, Wang GJ, Swanson JM. Dopamine in drug abuse and addiction: results from imaging studies and treatment implications. Molecular psychiatry 2004; 9(6): 557-69.

[11] Phillips PE, Stuber GD, Heien ML, Wightman RM, Carelli RM. Subsecond dopamine release promotes cocaine seeking. Nature 2003; 422(6932): 614-8.

[12] Robinson DL, Heien ML, Wightman RM. Frequency of dopamine concentration transients increases in dorsal and ventral striatum of male rats during introduction of conspecifics. J Neurosci 2002; 22(23): 10477-86.

[13] Robinson DL, Phillips PE, Budygin EA, Trafton BJ, Garris PA, Wightman RM. Sub-second changes in accumbal dopamine during sexual behavior in male rats. Neuroreport 2001; 12(11): 2549-52.

[14] Day JJ, Roitman MF, Wightman RM, Carelli RM. Associative learning mediates dynamic shifts in dopamine signaling in the nucleus accumbens. Nature neuroscience 2007; 10(8): 1020-8.

[15] Owesson-White CA, Cheer JF, Beyene M, Carelli RM, Wightman RM. Dynamic changes in accumbens dopamine correlate with learning during intracranial self-stimulation. Proc Natl Acad Sci U S A 2008; 105(33): 11957-62.

[16] Roitman MF, Stuber GD, Phillips PE, Wightman RM, Carelli RM. Dopamine operates as a subsecond modulator of food seeking. J Neurosci 2004; 24(6): 1265-71.

[17] Stuber GD, Klanker M, de Ridder B, et al. Reward-predictive cues enhance excitatory synaptic strength onto midbrain dopamine neurons. Science 2008; 321(5896): 1690-2.

[18] Sunsay C, Rebec GV. Real-time dopamine efflux in the nucleus accumbens core during Pavlovian conditioning. Behav Neurosci 2008; 122(2): 358-67.

[19] Swanson LW. The projections of the ventral tegmental area and adjacent regions: a combined fluorescent retrograde tracer and immunofluorescence study in the rat. Brain Res Bull 1982; 9(1-6): 321-53.

[20] Riederer P, Wuketich S. Time course of nigrostriatal degeneration in parkinson's disease. A detailed study of influential factors in human brain amine analysis. J Neural Transm 1976; 38(3-4): 277301.

[21] Nair-Roberts RG, Chatelain-Badie SD, Benson E, White-Cooper $\mathrm{H}$, Bolam JP, Ungless MA. Stereological estimates of dopaminergic, GABAergic and glutamatergic neurons in the ventral tegmental area, substantia nigra and retrorubral field in the rat. Neuroscience 2008; 152(4): 1024-31.

[22] Kawano M, Kawasaki A, Sakata-Haga H, et al. Particular subpopulations of midbrain and hypothalamic dopamine neurons express vesicular glutamate transporter 2 in the rat brain. J Comp Neurol 2006; 498(5): 581-92.

[23] Lapish CC, Kroener S, Durstewitz D, Lavin A, Seamans JK. The ability of the mesocortical dopamine system to operate in distinct temporal modes. Psychopharmacology (Berl) 2007; 191(3): 60925 .

[24] Yamaguchi T, Sheen W, Morales M. Glutamatergic neurons are present in the rat ventral tegmental area. Eur J Neurosci 2007; 25(1): 106-18.

[25] Omelchenko N, Sesack SR. Laterodorsal tegmental projections to identified cell populations in the rat ventral tegmental area. J Comp Neurol 2005; 483(2): 217-35.

[26] Phillipson OT. Afferent projections to the ventral tegmental area of Tsai and interfascicular nucleus: a horseradish peroxidase study in the rat. J Comp Neurol 1979 ; 187(1): 117-43.

[27] Forster GL, Blaha CD. Pedunculopontine tegmental stimulation evokes striatal dopamine efflux by activation of acetylcholine and glutamate receptors in the midbrain and pons of the rat. Eur $\mathbf{J}$ Neurosci 2003; 17(4): 751-62.
[28] Geisler S, Derst C, Veh RW, Zahm DS. Glutamatergic afferents of the ventral tegmental area in the rat. J Neurosci 2007; 27(21): 5730-43.

[29] Grace AA, Bunney BS. Intracellular and extracellular electrophysiology of nigral dopaminergic neurons--1. Identification and characterization. Neuroscience $1983 ; 10(2)$ : 301-15.

[30] Grace AA, Floresco SB, Goto Y, Lodge DJ. Regulation of firing of dopaminergic neurons and control of goal-directed behaviors. Trends Neurosci 2007; 30(5): 220-7.

[31] Anstrom KK, Woodward DJ. Restraint Increases Dopaminergic Burst Firing in Awake Rats. Neuropsychopharmacology 2005; 30(10): 1832-40

[32] Hyland BI, Reynolds JN, Hay J, Perk CG, Miller R. Firing modes of midbrain dopamine cells in the freely moving rat. Neuroscience 2002; 114(2): 475-92.

[33] Freeman AS, Bunney BS. Activity of A9 and A10 dopaminergic neurons in unrestrained rats: further characterization and effects of apomorphine and cholecystokinin. Brain Res 1987; 405(1): 46-55.

[34] Grace AA, Bunney BS. Intracellular and extracellular electrophysiology of nigral dopaminergic neurons--3. Evidence for electrotonic coupling. Neuroscience 1983; 10(2): 333-48.

[35] Mameli-Engvall M, Evrard A, Pons S, Maskos U, Svensson TH, Changeux JP, et al. Hierarchical control of dopamine neuron-firing patterns by nicotinic receptors. Neuron 2006 ; 50(6): 911-21.

[36] Kiyatkin EA, Rebec GV. Heterogeneity of ventral tegmental area neurons: single-unit recording and iontophoresis in awake, unrestrained rats. Neuroscience 1998 ; 85(4): 1285-309.

[37] Marinelli M, Rudick CN, Hu XT, White FJ. Excitability of dopamine neurons: modulation and physiological consequences. CNS Neurol Disord Drug Targets 2006 ; 5(1): 79-97.

[38] Overton PG, Clark D. Burst firing in midbrain dopaminergic neurons. Brain Res Brain Res Rev 1997; 25(3): 312-34.

[39] Lodge DJ, Grace AA. The laterodorsal tegmentum is essential for burst firing of ventral tegmental area dopamine neurons. Proc Natl Acad Sci U S A 2006; 103(13): 5167-72.

[40] Forster GL, Blaha CD. Laterodorsal tegmental stimulation elicits dopamine efflux in the rat nucleus accumbens by activation of acetylcholine and glutamate receptors in the ventral tegmental area. Eur J Neurosci 2000; 12(10): 3596-604.

[41] Margolis EB, Lock H, Hjelmstad GO, Fields HL. The ventral tegmental area revisited: is there an electrophysiological marker for dopaminergic neurons? J Physiol 2006; 577(Pt 3): 907-24.

[42] Ungless MA, Magill PJ, Bolam JP. Uniform inhibition of dopamine neurons in the ventral tegmental area by aversive stimuli. Science 2004; 303(5666): 2040-2.

[43] Mereu G, Lilliu V, Vargiu P, Muntoni AL, Diana M, Gessa GL. Depolarization inactivation of dopamine neurons: an artifact? J Neurosci 1995; 15(2): 1144-9.

[44] Fa M, Mereu G, Ghiglieri V, Meloni A, Salis P, Gessa GL. Electrophysiological and pharmacological characteristics of nigral dopaminergic neurons in the conscious, head-restrained rat. Synapse (New York, NY. 2003; 48(1): 1-9.

[45] Windels F, Kiyatkin EA. General anesthesia as a factor affecting impulse activity and neuronal responses to putative neurotransmitters. Brain res 2006 ; 1086(1): 104-16.

[46] Grace AA, Onn SP. Morphology and electrophysiological properties of immunocytochemically identified rat dopamine neurons recorded in vitro. J Neurosci 1989 Oct; 9(10): 3463-81.

[47] Neuhoff H, Neu A, Liss B, Roeper J. I(h) channels contribute to the different functional properties of identified dopaminergic subpopulations in the midbrain. J Neurosci 2002; 22(4): 1290-302.

[48] Wanat MJ, Hopf FW, Stuber GD, Phillips PE, Bonci A. Corticotropin-releasing factor increases mouse ventral tegmental area dopamine neuron firing through a protein kinase $\mathrm{C}$-dependent enhancement of Ih. J Physiol 2008; 586(8): 2157-70.

[49] Cameron DL, Wessendorf MW, Williams JT. A subset of ventral tegmental area neurons is inhibited by dopamine, 5hydroxytryptamine and opioids. Neuroscience 1997; 77(1): 155-66.

[50] Lammel S, Hetzel A, Hackel O, Jones I, Liss B, Roeper J. Unique properties of mesoprefrontal neurons within a dual mesocorticolimbic dopamine system. Neuron 2008 ; 57(5): 760-73.

[51] Margolis EB, Mitchell JM, Ishikawa J, Hjelmstad GO, Fields HL. Midbrain dopamine neurons: projection target determines action potential duration and dopamine $\mathrm{D}(2)$ receptor inhibition. J Neurosci 2008; 28(36): 8908-13. 
[52] Robinson DL, Hermans A, Seipel AT, Wightman RM. Monitoring rapid chemical communication in the brain. Chem Rev 2008; 108(7): 2554-84.

[53] Clapp-Lilly KL, Roberts RC, Duffy LK, Irons KP, Hu Y, Drew KL. An ultrastructural analysis of tissue surrounding a microdialysis probe. J neuroscie methods 1999; 90(2): 129-42.

[54] Bungay PM, Newton-Vinson P, Isele W, Garris PA, Justice JB. Microdialysis of dopamine interpreted with quantitative model incorporating probe implantation trauma. J Neurochem 2003; 86(4): 932-46.

[55] Venton BJ, Robinson TE, Kennedy RT, Maren S. Dynamic amino acid increases in the basolateral amygdala during acquisition and expression of conditioned fear. Eur J Neurosci 2006; 23(12): 33918.

[56] Parsons LH, Justice JB, Jr. Extracellular concentration and in vivo recovery of dopamine in the nucleus accumbens using microdialysis. J Neurochem 1992; 58(1): 212-8.

[57] Floresco SB, West AR, Ash B, Moore H, Grace AA. Afferent modulation of dopamine neuron firing differentially regulates tonic and phasic dopamine transmission. Nature neuroscience 2003; 6(9): 968-73.

[58] Phillips PE, Wightman RM. Critical guidelines for validation of the selectivity of in-vivo chemical microsensors. Trends Analyt Chem 2003; 22(9): 5 .

[59] Heien ML, Wightman RM. Phasic dopamine signaling during behavior, reward, and disease states. CNS Neurol Disord Drug Targets 2006 ; 5(1): 99-108.

[60] Robinson DL, Venton BJ, Heien ML, Wightman RM. Detecting subsecond dopamine release with fast-scan cyclic voltammetry in vivo. Clin Chem 2003 ; 49(10): 1763-73.

[61] Phillips PE, Robinson DL, Stuber GD, Carelli RM, Wightman RM. Real-time measurements of phasic changes in extracellular dopamine concentration in freely moving rats by fast-scan cyclic voltammetry. Methods Mol Med 2003; 79: 443-64.

[62] Heien ML, Khan AS, Ariansen JL, et al. Real-time measurement of dopamine fluctuations after cocaine in the brain of behaving rats. Proc Natl Acad Sci U S A 2005; 102(29): 10023-8.

[63] Garris PA, Christensen JR, Rebec GV, Wightman RM. Real-time measurement of electrically evoked extracellular dopamine in the striatum of freely moving rats. J Neurochem 1997; 68(1): 152-61.

[64] Gonon FG. Nonlinear relationship between impulse flow and dopamine released by rat midbrain dopaminergic neurons as studied by in vivo electrochemistry. Neuroscience 1988; 24(1): 1928.

[65] Carlsson A, Lindqvist M, Magnusson T. 3,4Dihydroxyphenylalanine and 5-hydroxytryptophan as reserpine antagonists. Nature 1957; 180(4596): 1200.

[66] Berridge KC. The debate over dopamine's role in reward: the case for incentive salience. Psychopharmacology (Berl) 2007; 191(3): 391-431.

[67] Redgrave P, Gurney K. The short-latency dopamine signal: a role in discovering novel actions? Nat Rev Neurosci 2006; 7(12): 96775.

[68] Salamone JD, Correa M. Motivational views of reinforcement: implications for understanding the behavioral functions of nucleus accumbens dopamine. Behav Brain Res 2002; 137(1-2): 3-25.

[69] Schultz W. Dopamine neurons and their role in reward mechanisms. Curr Opin Neurobiol 1997; 7(2): 191-7.

[70] Schultz W. Multiple dopamine functions at different time courses. Annu rev neuroscie 2007; 30: 259-88.

[71] Wise RA. Dopamine, learning and motivation. Nat Rev Neurosci 2004 ; 5(6): 483-94.

[72] Bergstrom BP, Garris PA. "Passive stabilization" of striatal extracellular dopamine across the lesion spectrum encompassing the presymptomatic phase of Parkinson's disease: a voltammetric study in the 6-OHDA-lesioned rat. J Neurochem. 2003; 87(5): 1224-36.

[73] Bezard E, Dovero S, Prunier C, et al. Relationship between the appearance of symptoms and the level of nigrostriatal degeneration in a progressive 1-methyl-4-phenyl-1,2,3,6-tetrahydropyridinelesioned macaque model of Parkinson's disease. J Neurosci 2001; 21(17): 6853-61.

[74] Zhou QY, Palmiter RD. Dopamine-deficient mice are severely hypoactive, adipsic, and aphagic. Cell 1995; 83(7): 1197-209.

[75] Cousins MS, Salamone JD. Nucleus accumbens dopamine depletions in rats affect relative response allocation in a novel cost/benefit procedure. Pharmacol Biochem Behav 1994; 49(1): 8591.

[76] Cousins MS, Sokolowski JD, Salamone JD. Different effects of nucleus accumbens and ventrolateral striatal dopamine depletions on instrumental response selection in the rat. Pharmacol Biochem Behav 1993; 46(4): 943-51.

[77] Nowend KL, Arizzi M, Carlson BB, Salamone JD. D1 or D2 antagonism in nucleus accumbens core or dorsomedial shell suppresses lever pressing for food but leads to compensatory increases in chow consumption. Pharmacol Biochem Behav 2001; 69(3-4): 373-82.

[78] Salamone JD, Steinpreis RE, McCullough LD, Smith P, Grebel D, Mahan K. Haloperidol and nucleus accumbens dopamine depletion suppress lever pressing for food but increase free food consumption in a novel food choice procedure. Psychopharmacology (Berl) 1991; 104(4): 515-21.

[79] Denk F, Walton ME, Jennings KA, Sharp T, Rushworth MF, Bannerman DM. Differential involvement of serotonin and dopamine systems in cost-benefit decisions about delay or effort. Psychopharmacology (Berl) 2005; 179(3): 587-96.

[80] Salamone JD, Cousins MS, Bucher S. Anhedonia or anergia? Effects of haloperidol and nucleus accumbens dopamine depletion on instrumental response selection in a T-maze cost/benefit procedure. Behav Brain Res 1994; 65(2): 221-9.

[81] Cousins MS, Atherton A, Turner L, Salamone JD. Nucleus accumbens dopamine depletions alter relative response allocation in a T-maze cost/benefit task. Behav Brain Res 1996; 74(1-2): 18997.

[82] Richardson NR, Roberts DC. Progressive ratio schedules in drug self-administration studies in rats: a method to evaluate reinforcing efficacy. J neurosci methods 1996 ; 66(1): 1-11.

[83] Aberman JE, Ward SJ, Salamone JD. Effects of dopamine antagonists and accumbens dopamine depletions on timeconstrained progressive-ratio performance. Pharmacol biochem behav 1998 ; 61(4): 341-8.

[84] Hamill S, Trevitt JT, Nowend KL, Carlson BB, Salamone JD. Nucleus accumbens dopamine depletions and time-constrained progressive ratio performance: effects of different ratio requirements. Pharmacol Biochem Behav 1999; 64(1): 21-7.

[85] Zhang M, Balmadrid C, Kelley AE. Nucleus accumbens opioid, GABaergic, and dopaminergic modulation of palatable food motivation: contrasting effects revealed by a progressive ratio study in the rat. Behav Neurosci 2003; 117(2): 202-11.

[86] Cagniard B, Balsam PD, Brunner D, Zhuang X. Mice with chronically elevated dopamine exhibit enhanced motivation, but not learning, for a food reward. Neuropsychopharmacology 20061; 31(7): 1362-70.

[87] Phillips PE, Walton ME, Jhou TC. Calculating utility: preclinical evidence for cost-benefit analysis by mesolimbic dopamine. Psychopharmacology (Berl) 2007; 191(3): 483-95.

[88] Berridge KC, Venier IL, Robinson TE. Taste reactivity analysis of 6-hydroxydopamine-induced aphagia: implications for arousal and anhedonia hypotheses of dopamine function. Behav neurosci 1989; 103(1): 36-45.

[89] Kaczmarek HJ, Kiefer SW. Microinjections of dopaminergic agents in the nucleus accumbens affect ethanol consumption but not palatability. Pharmacol Biochem Behav 2000 ; 66(2): 307-12.

[90] Pecina S, Berridge KC, Parker LA. Pimozide does not shift palatability: separation of anhedonia from sensorimotor suppression by taste reactivity. Pharmacolo Biochem Behav 1997; 58(3): 801-11.

[91] Pecina S, Cagniard B, Berridge KC, Aldridge JW, Zhuang X. Hyperdopaminergic mutant mice have higher "wanting" but not "liking" for sweet rewards. J Neurosci 2003; 23(28): 9395-402.

[92] Evans AH, Pavese N, Lawrence AD, et al. Compulsive drug use linked to sensitized ventral striatal dopamine transmission. Ann neurol 2006; 59(5): 852-8.

[93] Leyton M, Casey KF, Delaney JS, Kolivakis T, Benkelfat C. Cocaine craving, euphoria, and self-administration: a preliminary study of the effect of catecholamine precursor depletion. Behav neurosci 2005; 119(6): 1619-27.

[94] Pan WX, Schmidt R, Wickens JR, Hyland BI. Dopamine cells respond to predicted events during classical conditioning: evidence for eligibility traces in the reward-learning network. J Neurosci 2005; 25(26): 6235-42. 
[95] Schultz W, Dayan P, Montague PR. A neural substrate of prediction and reward. Science 1997; 275(5306): 1593-9.

[96] Fiorillo CD, Tobler PN, Schultz W. Discrete coding of reward probability and uncertainty by dopamine neurons. Science 2003; 299(5614): 1898-902.

[97] Kobayashi S, Schultz W. Influence of reward delays on responses of dopamine neurons. J Neurosci 2008 ; 28(31): 7837-46.

[98] Tobler PN, Fiorillo CD, Schultz W. Adaptive coding of reward value by dopamine neurons. Science 2005; 307(5715): 1642-5.

[99] Comoli E, Coizet V, Boyes J, et al. A direct projection from superior colliculus to substantia nigra for detecting salient visual events. Nat neurosci 2003; 6(9): 974-80.

[100] Daw ND, Niv Y, Dayan P. Uncertainty-based competition between prefrontal and dorsolateral striatal systems for behavioral control. Nat neurosci 2005; 8(12): 1704-11.

[101] Waelti P, Dickinson A, Schultz W. Dopamine responses comply with basic assumptions of formal learning theory. Nature 2001 ; 412(6842): 43-8.

[102] Montague PR, Dayan P, Sejnowski TJ. A framework for mesencephalic dopamine systems based on predictive Hebbian learning. J Neurosci 1996 ; 16(5): 1936-47.

[103] Montague PR, McClure SM, Baldwin PR, et al. Dynamic gain control of dopamine delivery in freely moving animals. J Neurosci 2004; 24(7): 1754-9.

[104] Inglis FM, Moghaddam B. Dopaminergic innervation of the amygdala is highly responsive to stress. J Neurochem 1999; 72(3): 1088-94.

[105] Fiorino DF, Coury A, Phillips AG. Dynamic changes in nucleus accumbens dopamine efflux during the Coolidge effect in male rats. J Neurosci 1997 ; 17(12): 4849-55.

[106] Roitman MF, Wheeler RA, Wightman RM, Carelli RM. Real-time chemical responses in the nucleus accumbens differentiate rewarding and aversive stimuli. Nat neurosci 2008; 11(12): 1376-7.

[107] You ZB, Chen YQ, Wise RA. Dopamine and glutamate release in the nucleus accumbens and ventral tegmental area of rat following lateral hypothalamic self-stimulation. Neuroscience 2001; 107(4): 629-39.

[108] Garris PA, Kilpatrick M, Bunin MA, Michael D, Walker QD, Wightman RM. Dissociation of dopamine release in the nucleus accumbens from intracranial self-stimulation. Nature 1999; 398(6722): 67-9.

[109] Cheer JF, Heien ML, Garris PA, Carelli RM, Wightman RM. Simultaneous dopamine and single-unit recordings reveal accumbens GABAergic responses: implications for intracranial self-stimulation. Proc Natl Acad Sci U S A 2005 ; 102(52): 191505.

[110] Di Chiara G, Imperato A. Drugs abused by humans preferentially increase synaptic dopamine concentrations in the mesolimbic system of freely moving rats. Proc Natl Acad Sci U S A 1988; 85(14): 5274-8.

[111] Tanda G, Pontieri FE, Di Chiara G. Cannabinoid and heroin activation of mesolimbic dopamine transmission by a common mu 1 opioid receptor mechanism. Science 1997; 276(5321): 2048-50.

[112] Kuhr WG, Ewing AG, Near JA, Wightman RM. Amphetamine attenuates the stimulated release of dopamine in vivo. J Pharmacol Exp Ther $1985 ; 232(2)$ : 388-94.

[113] Ritz MC, Lamb RJ, Goldberg SR, Kuhar MJ. Cocaine receptors on dopamine transporters are related to self-administration of cocaine. Science 1987 ; 237(4819): 1219-23.

[114] Iwatsubo K, Clouet DH. Effects of morphine and haloperidol on the electrical activity of rat nigrostriatal neurons. J Pharmacol Exp Ther 1977 Aug; 202(2): 429-36.

[115] Melis M, Gessa GL, Diana M. Different mechanisms for dopaminergic excitation induced by opiates and cannabinoids in the rat midbrain. Prog Neuro-psychopharmacol Biol Psychiatry 2000 Aug; 24(6): 993-1006.

[116] Cheer JF, Marsden CA, Kendall DA, Mason R. Lack of response suppression follows repeated ventral tegmental cannabinoid administration: an in vitro electrophysiological study. Neuroscience 2000; 99(4): 661-7.

[117] Szabo B, Siemes S, Wallmichrath I. Inhibition of GABAergic neurotransmission in the ventral tegmental area by cannabinoids. Eur J Neurosci 2002; 15(12): 2057-61.

[118] Gallegos RA, Lee RS, Criado JR, Henriksen SJ, Steffensen SC. Adaptive responses of gamma-aminobutyric acid neurons in the ventral tegmental area to chronic ethanol. J Pharmacol Exp Ther 1999; 291(3): 1045-53.

[119] Brodie MS, Appel SB. Dopaminergic neurons in the ventral tegmental area of $\mathrm{C} 57 \mathrm{BL} / 6 \mathrm{~J}$ and DBA/2J mice differ in sensitivity to ethanol excitation. Alcohol Clin Exp Res 2000; 24(7): 1120-4.

[120] Koyama S, Brodie MS, Appel SB. Ethanol inhibition of m-current and ethanol-induced direct excitation of ventral tegmental area dopamine neurons. J Neurophysiol 2007; 97(3): 1977-85.

[121] Okamoto T, Harnett MT, Morikawa H. Hyperpolarization-activated cation current (Ih) is an ethanol target in midbrain dopamine neurons of mice. J Neurophysiol 2006; 95(2): 619-26.

[122] Theile JW, Morikawa H, Gonzales RA, Morrisett RA. Ethanol enhances GABAergic transmission onto dopamine neurons in the ventral tegmental area of the rat. Alcohol Clin Exp Res 2008; 32(6): 1040-8.

[123] Xiao C, Shao XM, Olive MF, et al. Ethanol Facilitates Glutamatergic Transmission to Dopamine Neurons in the Ventral Tegmental Area. Neuropsychopharmacology 2008; 34(2): 30718. Epub 2008 Jul 2

[124] Mansvelder HD, Keath JR, McGehee DS. Synaptic mechanisms underlie nicotine-induced excitability of brain reward areas. Neuron 2002; 33(6): 905-19.

[125] Pidoplichko VI, DeBiasi M, Williams JT, Dani JA. Nicotine activates and desensitizes midbrain dopamine neurons. Nature 1997; 390(6658): 401-4.

[126] Mansvelder HD, McGehee DS. Long-term potentiation of excitatory inputs to brain reward areas by nicotine. Neuron 2000; 27(2): 349-57.

[127] French ED, Dillon K, Wu X. Cannabinoids excite dopamine neurons in the ventral tegmentum and substantia nigra. Neuroreport 1997; 8(3): 649-52.

[128] Gessa GL, Melis M, Muntoni AL, Diana M. Cannabinoids activate mesolimbic dopamine neurons by an action on cannabinoid CB1 receptors. EurJ Pharmacol 1998; 341(1): 39-44.

[129] Einhorn LC, Johansen PA, White FJ. Electrophysiological effects of cocaine in the mesoaccumbens dopamine system: studies in the ventral tegmental area. J Neurosci 1988; 8(1): 100-12.

[130] Lacey MG, Mercuri NB, North RA. Actions of cocaine on rat dopaminergic neurones in vitro. Br J Pharmacol 1990; 99(4): 7315 .

[131] Sanghera MK, Trulson ME, German DC. Electrophysiological properties of mouse dopamine neurons: in vivo and in vitro studies. Neuroscience 1984; 12(3): 793-801.

[132] Kiyatkin EA, Rebec GV. Activity of presumed dopamine neurons in the ventral tegmental area during heroin self-administration. Neuroreport 1997; 8(11): 2581-5.

[133] Kiyatkin EA, Rebec GV. Impulse activity of ventral tegmental area neurons during heroin self-administration in rats. Neuroscience 2001; 102(3): 565-80.

[134] Kalivas PW, Duffy P. Time course of extracellular dopamine and behavioral sensitization to cocaine. I. Dopamine axon terminals. J Neurosci 1993; 13(1): 266-75.

[135] Meil WM, Roll JM, Grimm JW, Lynch AM, See RE. Tolerancelike attenuation to contingent and noncontingent cocaine-induced elevation of extracellular dopamine in the ventral striatum following 7 days of withdrawal from chronic treatment. Psychopharmacology (Berl) 1995; 118(3): 338-46.

[136] Pettit HO, Pan HT, Parsons LH, Justice JB, Jr. Extracellular concentrations of cocaine and dopamine are enhanced during chronic cocaine administration. J Neurochem 1990; 55(3): 798804.

[137] Pettit HO, Justice JB, Jr. Dopamine in the nucleus accumbens during cocaine self-administration as studied by in vivo microdialysis. Pharmacol Biochem Behav 198934(4): 899-904.

[138] Pettit HO, Justice JB, Jr. Effect of dose on cocaine selfadministration behavior and dopamine levels in the nucleus accumbens. Brain Res 1991; 539(1): 94-102.

[139] Wise RA, Newton P, Leeb K, Burnette B, Pocock D, Justice JB, Jr. Fluctuations in nucleus accumbens dopamine concentration during intravenous cocaine self-administration in rats. Psychopharmacology (Berl) 1995; 120(1): 10-20.

[140] Ranaldi R, Pocock D, Zereik R, Wise RA. Dopamine fluctuations in the nucleus accumbens during maintenance, extinction, and reinstatement of intravenous D-amphetamine self-administration. J Neurosci 1999; 19(10): 4102-9. 
[141] Wise RA, Leone P, Rivest R, Leeb K. Elevations of nucleus accumbens dopamine and DOPAC levels during intravenous heroin self-administration. Synapse (New York, NY 1995; 21(2): 140-8.

[142] Liu ZH, Jin WQ. Decrease of ventral tegmental area dopamine neuronal activity in nicotine withdrawal rats. Neuroreport 2004; 15(9): 1479-81.

[143] Bailey CP, Manley SJ, Watson WP, Wonnacott S, Molleman A, Little HJ. Chronic ethanol administration alters activity in ventral tegmental area neurons after cessation of withdrawal hyperexcitability. Brain Res 1998; 803(1-2): 144-52.

[144] Diana M, Pistis M, Carboni S, Gessa GL, Rossetti ZL. Profound decrement of mesolimbic dopaminergic neuronal activity during ethanol withdrawal syndrome in rats: electrophysiological and biochemical evidence. Proc Natl Acad Sci U S A 1993; 90(17): 7966-9.

[145] Diana M, Muntoni AL, Pistis M, Melis M, Gessa GL. Lasting reduction in mesolimbic dopamine neuronal activity after morphine withdrawal. Eur J Neurosci 1999 ; 11(3): 1037-41.

[146] Diana M, Pistis M, Muntoni A, Gessa G. Profound decrease of mesolimbic dopaminergic neuronal activity in morphine withdrawn rats. J Pharmacol Exp Ther 1995; 272(2): 781-5.

[147] Georges F, Le Moine C, Aston-Jones G. No effect of morphine on ventral tegmental dopamine neurons during withdrawal. J Neurosci 2006; 26(21): 5720-6.

[148] Shen RY, Chiodo LA. Acute withdrawal after repeated ethanol treatment reduces the number of spontaneously active dopaminergic neurons in the ventral tegmental area. Brain Res 1993; 622(1-2): 289-93.

[149] Wu X, French ED. Effects of chronic delta9-tetrahydrocannabinol on rat midbrain dopamine neurons: an electrophysiological assessment. Neuropharmacology 2000 ; 39(3): 391-8.

[150] Kamata K, Rebec GV. Dopaminergic and neostriatal neurons: dose-dependent changes in sensitivity to amphetamine following long-term treatment. Neuropharmacology 1983; 22(12A): 1377-82.

[151] Kamata K, Rebec GV. Long-term amphetamine treatment attenuates or reverses the depression of neuronal activity produced by dopamine agonists in the ventral tegmental area. Life sci 1984; 34(24): 2419-27.

[152] Kamata K, Rebec GV. Nigral dopaminergic neurons: differential sensitivity to apomorphine following long-term treatment with low and high doses of amphetamine. Brain Res 1984; 321(1): 147-50.

[153] Wolf ME, White FJ, Nassar R, Brooderson RJ, Khansa MR. Differential development of autoreceptor subsensitivity and enhanced dopamine release during amphetamine sensitization. J Pharmacol Exp Ther 1993; 264(1): 249-55.

[154] Henry DJ, Greene MA, White FJ. Electrophysiological effects of cocaine in the mesoaccumbens dopamine system: repeated administration. J Parmacol Exp Ther 1989 ; 251(3): 833-9.

[155] Marinelli M, Cooper DC, Baker LK, White FJ. Impulse activity of midbrain dopamine neurons modulates drug-seeking behavior. Psychopharmacology (Berl) 2003 ; 168(1-2): 84-98.

[156] Ackerman JM, White FJ. Decreased activity of rat A10 dopamine neurons following withdrawal from repeated cocaine. Eur $\mathrm{J}$ Pharmacol 1992; 218(1): 171-3.

[157] Gao WY, Lee TH, King GR, Ellinwood EH. Alterations in baseline activity and quinpirole sensitivity in putative dopamine neurons in the substantia nigra and ventral tegmental area after withdrawal from cocaine pretreatment. Neuropsychopharmacology 1998; 18(3): 222-32

[158] Termorshuizen F, Krol A, Prins M, Geskus R, van den Brink W, van Ameijden EJ. Prediction of relapse to frequent heroin use and the role of methadone prescription: an analysis of the Amsterdam Cohort Study among drug users. Drug Alcohol Depend 2005; 79(2): 231-40.

[159] Termorshuizen F, Krol A, Prins M, van Ameijden EJ. Long-term outcome of chronic drug use: the Amsterdam Cohort Study among Drug Users. Am J Epidemiol 2005; 161(3): 271-9.

[160] Sinha R, Fuse T, Aubin LR, O'Malley SS. Psychological stress, drug-related cues and cocaine craving. Psychopharmacology (Berl) 2000; 152(2): 140-8.

[161] Grimm JW, Hope BT, Wise RA, Shaham Y. Neuroadaptation. Incubation of cocaine craving after withdrawal. Nature 2001; 412(6843): 141-2.

[162] Shen RY, Choong KC, Thompson AC. Long-term reduction in ventral tegmental area dopamine neuron population activity following repeated stimulant or ethanol treatment. Bio Psychiatry 2007 ; 61(1): 93-100.

[163] Clay LH, Mazzio EA, Kolta MG, Soliman KF. Repeated administration of cocaine alters dopamine uptake and release in the striatum nucleus accumbens. Ann N Y A Sci 1998 ; 844: 346-55.

[164] Imperato A, Mele A, Scrocco MG, Puglisi-Allegra S. Chronic cocaine alters limbic extracellular dopamine. Neurochemical basis for addiction. Eur J Pharmacol1992; 212(2-3): 299-300.

[165] Parsons LH, Smith AD, Justice JB, Jr. Basal extracellular dopamine is decreased in the rat nucleus accumbens during abstinence from chronic cocaine. Synapse 1991; 9(1): 60-5.

[166] Robertson MW, Leslie CA, Bennett JP, Jr. Apparent synaptic dopamine deficiency induced by withdrawal from chronic cocaine treatment. Brain Res 1991 ; 538(2): 337-9.

[167] Rossetti ZL, Hmaidan Y, Gessa GL. Marked inhibition of mesolimbic dopamine release: a common feature of ethanol, morphine, cocaine and amphetamine abstinence in rats. Eur $\mathbf{J}$ Pharmacol $1992 ; 221(2-3)$ : 227-34.

[168] Weiss F, Markou A, Lorang MT, Koob GF. Basal extracellular dopamine levels in the nucleus accumbens are decreased during cocaine withdrawal after unlimited-access self-administration. Brain Res 1992; 593(2): 314-8.

[169] Zhang Y, Schlussman SD, Ho A, Kreek MJ. Effect of chronic "binge cocaine" on basal levels and cocaine-induced increases of dopamine in the caudate putamen and nucleus accumbens of C57BL/6J and 129/J mice. Synapse 2003 ; 50(3): 191-9.

[170] Chefer VI, Shippenberg TS. Changes in basal and cocaine-evoked extracellular dopamine uptake and release in the rat nucleus accumbens during early abstinence from cocaine: quantitative determination under transient conditions. Neuroscience 2002; 112(4): 907-19.

[171] Claye LH, Akunne HC, Davis MD, DeMattos S, Soliman KF. Behavioral and neurochemical changes in the dopaminergic system after repeated cocaine administration. Mol Neurobiol 1995; 11(13): 55-66.

[172] Crippens D, Camp DM, Robinson TE. Basal extracellular dopamine in the nucleus accumbens during amphetamine withdrawal: a 'no net flux' microdialysis study. Neurosci Lett 1993 Dec $24 ; 164(1-2): 145-8$.

[173] Heidbreder CA, Thompson AC, Shippenberg TS. Role of extracellular dopamine in the initiation and long-term expression of behavioral sensitization to cocaine. J Pharmacol Exp Ther 1996; 278(2): 490-502.

[174] Hooks MS, Duffy P, Striplin C, Kalivas PW. Behavioral and neurochemical sensitization following cocaine self-administration. Psychopharmacology (Berl) 1994; 115(1-2): 265-72.

[175] Kuczenski R, Segal DS, Todd PK. Behavioral sensitization and extracellular dopamine responses to amphetamine after various treatments. Psychopharmacology (Berl) 1997; 134(3): 221-9.

[176] Segal DS, Kuczenski R. In vivo microdialysis reveals a diminished amphetamine-induced DA response corresponding to behavioral sensitization produced by repeated amphetamine pretreatment. Brain Res 1992; 571(2): 330-7.

[177] Johnson DW, Glick SD. Dopamine release and metabolism in nucleus accumbens and striatum of morphine-tolerant and nontolerant rats. Pharmaco Biochem Behav 1993 ; 46(2): 341-7.

[178] Weiss F, Paulus MP, Lorang MT, Koob GF. Increases in extracellular dopamine in the nucleus accumbens by cocaine are inversely related to basal levels: effects of acute and repeated administration. J Neurosci 1992; 12(11): 4372-80.

[179] Pierce RC, Kalivas PW. Amphetamine produces sensitized increases in locomotion and extracellular dopamine preferentially in the nucleus accumbens shell of rats administered repeated cocaine. J Pharmacol Exp The 1995; 275(2): 1019-29.

[180] Segal DS, Kuczenski R. Repeated cocaine administration induces behavioral sensitization and corresponding decreased extracellular dopamine responses in caudate and accumbens. Brain Res 1992 ; 577(2): 351-5.

[181] Segal DS, Kuczenski R. An escalating dose "binge" model of amphetamine psychosis: behavioral and neurochemical characteristics. J Neurosci 1997; 17(7): 2551-66.

[182] Kolta MG, Shreve P, De Souza V, Uretsky NJ. Time course of the development of the enhanced behavioral and biochemical responses to amphetamine after pretreatment with amphetamine. Neuropharmacology 1985; 24(9): 823-9. 
[183] Paulson PE, Robinson TE. Amphetamine-induced time-dependent sensitization of dopamine neurotransmission in the dorsal and ventral striatum: a microdialysis study in behaving rats. Synapse $1995 ; 19(1): 56-65$.

[184] Robinson TE, Jurson PA, Bennett JA, Bentgen KM. Persistent sensitization of dopamine neurotransmission in ventral striatum (nucleus accumbens) produced by prior experience with (+)amphetamine: a microdialysis study in freely moving rats. Brain Res 1988; 462(2): 211-22.

[185] Harmer CJ, Phillips GD. Enhanced conditioned inhibition following repeated pretreatment with d-amphetamine. Psychopharmacology (Berl) 1999; 142(2): 120-31.

[186] Williams JE, Wieczorek W, Willner P, Kruk ZL. Parametric analysis of the effects of cocaine and cocaine pretreatment on dopamine release in the nucleus accumbens measured by fast cyclic voltammetry. Brain Res 1995; 678(1-2): 225-32.

[187] Wilson JM, Nobrega JN, Carroll ME, et al. Heterogeneous subregional binding patterns of $3 \mathrm{H}-\mathrm{WIN} 35,428$ and $3 \mathrm{H}-\mathrm{GBR}$ 12,935 are differentially regulated by chronic cocaine selfadministration. J Neurosci 1994; 14(5 Pt 2): 2966-79.

[188] Hitri A, Little KY, Ellinwood EH, Jr. Effect of cocaine on dopamine transporter receptors depends on routes of chronic cocaine administration. Neuropsychopharmacology 1996; 14(3): 205-10.

[189] Pilotte NS, Sharpe LG, Kuhar MJ. Withdrawal of repeated intravenous infusions of cocaine persistently reduces binding to dopamine transporters in the nucleus accumbens of Lewis rats. J Pharmacol Exp Ther 1994; 269(3): 963-9.

[190] Pilotte NS, Sharpe LG, Rountree SD, Kuhar MJ. Cocaine withdrawal reduces dopamine transporter binding in the shell of the nucleus accumbens. Synapse 1996 ; 22(1): 87-92.

[191] Sharpe LG, Pilotte NS, Mitchell WM, De Souza EB. Withdrawal of repeated cocaine decreases autoradiographic [3H]mazindollabelling of dopamine transporter in rat nucleus accumbens. Eur $\mathbf{J}$ Pharmacol 1991; 203(1): 141-4.

[192] Cass WA, Gerhardt GA, Gillespie K, Curella P, Mayfield RD, Zahniser NR. Reduced clearance of exogenous dopamine in rat nucleus accumbens, but not in dorsal striatum, following cocaine challenge in rats withdrawn from repeated cocaine administration. $\mathbf{J}$ Neurochem 1993 ; 61(1): 273-83.

[193] Izenwasser S, Cox BM. Daily cocaine treatment produces a persistent reduction of $[3 \mathrm{H}]$ dopamine uptake in vitro in rat nucleus accumbens but not in striatum. Brain Res 1990; 531(1-2): 338-41.

[194] Bellone C, Luscher C. Cocaine triggered AMPA receptor redistribution is reversed in vivo by mGluR-dependent long-term depression. Nat neurosci 2006 ; 9(5): 636-41.

[195] Borgland SL, Malenka RC, Bonci A. Acute and chronic cocaineinduced potentiation of synaptic strength in the ventral tegmental area: electrophysiological and behavioral correlates in individual rats. J Neurosci 2004; 24(34): 7482-90.

[196] Liu QS, Pu L, Poo MM. Repeated cocaine exposure in vivo facilitates LTP induction in midbrain dopamine neurons. Nature 2005; 437(7061): 1027-31.

[197] Saal D, Dong Y, Bonci A, Malenka RC. Drugs of abuse and stress trigger a common synaptic adaptation in dopamine neurons. Neuron 2003; 37(4): 577-82.

[198] Ungless MA, Whistler JL, Malenka RC, Bonci A. Single cocaine exposure in vivo induces long-term potentiation in dopamine neurons. Nature 2001; 411(6837): 583-7.

[199] Wanat MJ, Bonci A. Dose-dependent changes in the synaptic strength on dopamine neurons and locomotor activity after cocaine exposure. Synapse 2008 ; 62(10): 790-5.

[200] Gao C, Wolf ME. Dopamine alters AMPA receptor synaptic expression and subunit composition in dopamine neurons of the ventral tegmental area cultured with prefrontal cortex neurons. J Neurosci 2007; 27(52): 14275-85.

[201] Argilli E, Sibley DR, Malenka RC, England PM, Bonci A. Mechanism and time course of cocaine-induced long-term potentiation in the ventral tegmental area. J Neurosci 2008; 28(37): 9092-100.

[202] Faleiro LJ, Jones S, Kauer JA. Rapid synaptic plasticity of glutamatergic synapses on dopamine neurons in the ventral tegmental area in response to acute amphetamine injection. Neuropsychopharmacology 2004; 29(12): 2115-25.

[203] Schilstrom B, Yaka R, Argilli E, et al. Cocaine enhances NMDA receptor-mediated currents in ventral tegmental area cells via dopamine D5 receptor-dependent redistribution of NMDA receptors. J Neurosci 2006; 26(33): 8549-58.

[204] Wang F, Chen H, Steketee JD, Sharp BM. Upregulation of ionotropic glutamate receptor subunits within specific mesocorticolimbic regions during chronic nicotine selfadministration. Neuropsychopharmacology 2007 ; 32(1): 103-9.

[205] Chen BT, Bowers MS, Martin M, et al. Cocaine but not natural reward self-administration nor passive cocaine infusion produces persistent LTP in the VTA. Neuron 2008; 59(2): 288-97.

[206] Engblom D, Bilbao A, Sanchis-Segura C, et al. Glutamate receptors on dopamine neurons control the persistence of cocaine seeking. Neuron 2008; 59(3): 497-508.

[207] Nugent FS, Penick EC, Kauer JA. Opioids block long-term potentiation of inhibitory synapses. Nature 2007; 446(7139): 108690.

[208] Melis M, Camarini R, Ungless MA, Bonci A. Long-lasting potentiation of GABAergic synapses in dopamine neurons after a single in vivo ethanol exposure. J Neurosci 2002; 22(6): 2074-82.

[209] Wanat MJ, Sparta DR, Hopf FW, Bowers MS, Melis M, Bonci A. Strain Specific Synaptic Modifications on Ventral Tegmental Area Dopamine Neurons After Ethanol Exposure. Biol Psychiatry 2008 Dec 30 Epub ahead of printing

[210] Hopf FW, Martin M, Chen BT, Bowers MS, Mohamedi MM Bonci A. Withdrawal from intermittent ethanol exposure increases probability of burst firing in VTA neurons in vitro. J Neurophysiol 2007 ; 98(4): 2297-310.

[211] Canavier CC, Landry RS. An increase in AMPA and a decrease in SK conductance increase burst firing by different mechanisms in a model of a dopamine neuron in vivo. J Neurophysiol2006; 96(5): 2549-63.

[212] Budygin EA, Phillips PE, Wightman RM, Jones SR. Terminal effects of ethanol on dopamine dynamics in rat nucleus accumbens: an in vitro voltammetric study. Synapse $2001 ; 42(2)$ : 77-9.

[213] Mathews TA, John CE, Lapa GB, Budygin EA, Jones SR. No role of the dopamine transporter in acute ethanol effects on striatal dopamine dynamics. Synapse 2006; 60(4): 288-94.

[214] Samson HH, Hodge CW, Erickson HL, et al. The effects of local application of ethanol in the $n$. accumbens on dopamine overflow and clearance. Alcohol 1997; 14(5): 485-92.

[215] Budygin EA, Oleson EB, Mathews TA, et al. Effects of chronic alcohol exposure on dopamine uptake in rat nucleus accumbens and caudate putamen. Psychopharmacology (Berl) 2007; 193(4): 495-501.

[216] Budygin EA, Phillips PE, Robinson DL, Kennedy AP, Gainetdinov RR, Wightman RM. Effect of acute ethanol on striatal dopamine neurotransmission in ambulatory rats. J Pharmacol Exp Ther 2001 ; 297(1): 27-34.

[217] Cheer JF, Wassum KM, Sombers LA, et al. Phasic dopamine release evoked by abused substances requires cannabinoid receptor activation. J Neurosci 2007; 27(4): 791-5.

[218] Cheer JF, Wassum KM, Heien ML, Phillips PE, Wightman RM. Cannabinoids enhance subsecond dopamine release in the nucleus accumbens of awake rats. J Neurosci 2004; 24(18): 4393-400.

[219] Middleton LS, Cass WA, Dwoskin LP. Nicotinic receptor modulation of dopamine transporter function in rat striatum and medial prefrontal cortex. J PharmacolExp Ther 2004; 308(1): 367 77.

[220] Rice ME, Cragg SJ. Nicotine amplifies reward-related dopamine signals in striatum. Nat Neurosci 2004; 7(6): 583-4.

[221] Zhang H, Sulzer D. Frequency-dependent modulation of dopamine release by nicotine. Nat Neurosci 2004; 7(6): 581-2.

[222] Aragona BJ, Cleaveland NA, Stuber GD, Day JJ, Carelli RM, Wightman RM. Preferential enhancement of dopamine transmission within the nucleus accumbens shell by cocaine is attributable to a direct increase in phasic dopamine release events. J Neurosci 2008; 28(35): 8821-31

[223] Stuber GD, Roitman MF, Phillips PE, Carelli RM, Wightman RM. Rapid dopamine signaling in the nucleus accumbens during contingent and noncontingent cocaine administration. Neuropsychopharmacology 2005; 30(5): 853-63.

[224] Stuber GD, Wightman RM, Carelli RM. Extinction of cocaine selfadministration reveals functionally and temporally distinct dopaminergic signals in the nucleus accumbens. Neuron 2005; 46(4): 661-9

[225] Riegel AC, Lupica CR. Independent presynaptic and postsynaptic mechanisms regulate endocannabinoid signaling at multiple 
synapses in the ventral tegmental area. J Neurosci 2004; 24(49): 11070-8.

[226] Robinson TE, Camp DM. Does amphetamine preferentially increase the extracellular concentration of dopamine in the mesolimbic system of freely moving rats? Neuropsychopharmacology 1990; 3(3): 163-73.

[227] Frank ST, Krumm B, Spanagel R. Cocaine-induced dopamine overflow within the nucleus accumbens measured by in vivo microdialysis: a meta-analysis. Synapse 2008; 62(4): 243-52.

[228] Sandberg SG, Clark JJ, Evans SB, Gan JO, Wanat MJ, Phillips PE. Long-term chronic microsensors for multisite, real-time dopamine detection in behaving animals. Monitoring Molecules in Neuroscience: Proceedings of the 12th International Conference on In Vivo Methods. 2008 2008: 2.

[229] Fowler JS, Volkow ND, Kassed CA, Chang L. Imaging the addicted human brain. Science \& practice perspectives / a publication of the National Institute on Drug Abuse, National Institutes of Health 2007 ; 3(2): 4-16.

[230] D'Ardenne K, McClure SM, Nystrom LE, Cohen JD. BOLD responses reflecting dopaminergic signals in the human ventral tegmental area. Science 2008; 319(5867): 1264-7.

[231] Schott BH, Minuzzi L, Krebs RM, et al. Mesolimbic functional magnetic resonance imaging activations during reward anticipation correlate with reward-related ventral striatal dopamine release. J Neurosci 2008; 28(52): 14311-9.

[232] Drevets WC, Gautier C, Price JC, Kupfer DJ, Kinahan PE, Grace AA, et al. Amphetamine-induced dopamine release in human ventral striatum correlates with euphoria. Biol Psychiatry 2001; 49(2): 81-96.

[233] Volkow ND, Wang GJ, Fischman MW, Foltin RW, Fowler JS, Abumrad NN, et al. Relationship between subjective effects of cocaine and dopamine transporter occupancy. Nature 1997; 386(6627): 827-30.

[234] Volkow ND, Wang GJ, Fowler JS, et al. Reinforcing effects of psychostimulants in humans are associated with increases in brain dopamine and occupancy of $\mathrm{D}(2)$ receptors. J Pharmacol Exp The 1999; 291(1): 409-15.

[235] Volkow ND, Wang GJ, Fowler JS, et al. Decreased striatal dopaminergic responsiveness in detoxified cocaine-dependent subjects. Nature 1997; 386(6627): 830-3.

[236] Volkow ND, Wang GJ, Fowler JS, et al. Decreases in dopamine receptors but not in dopamine transporters in alcoholics. Alcohol Clin Exp Res 1996; 20(9): 1594-8.

[237] Volkow ND, Fowler JS, Wolf AP, et al. Effects of chronic cocaine abuse on postsynaptic dopamine receptors. Am J Psychiatry 1990; 147(6): 719-24.

[238] Wang GJ, Volkow ND, Fowler JS, et al. Dopamine D2 receptor availability in opiate-dependent subjects before and after naloxoneprecipitated withdrawal. Neuropsychopharmacology 1997; 16(2): 174-82.

[239] Volkow ND, Chang L, Wang GJ, et al. Low level of brain dopamine D2 receptors in methamphetamine abusers: association with metabolism in the orbitofrontal cortex. Am J Psychiatry 2001; 158(12): 2015-21.

[240] Volkow ND, Wang GJ, Begleiter H, et al. High levels of dopamine D2 receptors in unaffected members of alcoholic families: possible protective factors. Arch Gen Psychiatry 2006; 63(9): 999-1008.

[241] Dalley JW, Fryer TD, Brichard L, et al. Nucleus accumbens D2/3 receptors predict trait impulsivity and cocaine reinforcement. Science 2007; 315(5816): 1267-70.
[242] Nader MA, Morgan D, Gage HD, et al. PET imaging of dopamine D2 receptors during chronic cocaine self-administration in monkeys. Nat Neurosci 2006 ; 9(8): 1050-6.

[243] Martinez D, Broft A, Foltin RW, et al. Cocaine dependence and d2 receptor availability in the functional subdivisions of the striatum: relationship with cocaine-seeking behavior. Neuropsychopharmacology 2004; 29(6): 1190-202.

[244] Chang L, Haning W. Insights from recent positron emission tomographic studies of drug abuse and dependence. Curr Opin Psychiatry 2006; 19(3): 246-52.

[245] Heinz A, Siessmeier T, Wrase J, et al. Correlation of alcohol craving with striatal dopamine synthesis capacity and $\mathrm{D} 2 / 3$ receptor availability: a combined [18F]DOPA and [18F]DMFP PET study in detoxified alcoholic patients. Am J Psychiatry. 2005; 162(8): $1515-20$

[246] Heinz A, Siessmeier T, Wrase J, et al. Correlation between dopamine $\mathrm{D}(2)$ receptors in the ventral striatum and central processing of alcohol cues and craving. Am J Psychiatry 2004; 161(10): 1783-9.

[247] Volkow ND, Wang GJ, Telang F, et al. Cocaine cues and dopamine in dorsal striatum: mechanism of craving in cocaine addiction. J Neurosci 2006; 26(24): 6583-8.

[248] Due DL, Huettel SA, Hall WG, Rubin DC. Activation in mesolimbic and visuospatial neural circuits elicited by smoking cues: evidence from functional magnetic resonance imaging. Am J Psychiatry 2002; 159(6): 954-60.

[249] Boileau I, Dagher A, Leyton M, et al. Conditioned dopamine release in humans: a positron emission tomography [11C]raclopride study with amphetamine. J Neurosci 2007 ; 27(15): 3998-4003.

[250] Nicola SM, Surmeier J, Malenka RC. Dopaminergic modulation of neuronal excitability in the striatum and nucleus accumbens. Annu Rev Neurosci 2000; 23: 185-215.

[251] O'Donnell P. Dopamine gating of forebrain neural ensembles. Eur J Neurosci 2003; 17(3): 429-35.

[252] Nelson A, Killcross S. Amphetamine exposure enhances habit formation. J Neurosci 2006; 26(14): 3805-12.

[253] Harmer CJ, Phillips GD. Enhanced appetitive conditioning following repeated pretreatment with d-amphetamine. Behav Pharmacol 1998 ; 9(4): 299-308.

[254] Bechara A, Dolan S, Denburg N, Hindes A, Anderson SW, Nathan PE. Decision-making deficits, linked to a dysfunctional ventromedial prefrontal cortex, revealed in alcohol and stimulant abusers. Neuropsychologia 2001; 39(4): 376-89.

[255] Ersche KD, Roiser JP, Robbins TW, Sahakian BJ. Chronic cocaine but not chronic amphetamine use is associated with perseverative responding in humans. Psychopharmacology (Berl) 2008; 197(3) 421-31.

[256] Sevy S, Hassoun Y, Bechara A, et al. Emotion-based decisionmaking in healthy subjects: short-term effects of reducing dopamine levels. Psychopharmacology (Berl) 2006; 188(2): 22835.

[257] Redish AD. Addiction as a computational process gone awry. Science 2004 ; 306(5703): 1944-7.

[258] Lacey MG, Mercuri NB, North RA. Dopamine acts on D2 receptors to increase potassium conductance in neurones of the rat substantia nigra zona compacta. J Physiol 1987; 392: 397-416.

[259] Cragg SJ, Greenfield SA. Differential autoreceptor control of somatodendritic and axon terminal dopamine release in substantia nigra, ventral tegmental area, and striatum. J Neurosci 1997; 17(15): $5738-46$ 